\title{
Functionalised Multi-walled Carbon Nanotubes/Cellulose Acetate Butyrate Mixed Matrix Membrane for $\mathrm{CO}_{2} / \mathrm{N}_{2}$ Separation
}

\author{
Shin Tien Lee, Jia Ni Pang and Zeinab Abbas Jawad* \\ Department of Chemical Engineering, Faculty of Engineering and Science, \\ Curtin University Malaysia, CDT 250, 98009 Miri, Sarawak, Malaysia \\ *Corresponding author: zeinab.aj@curtin.edu.my
}

Published online: 25 August 2019

To cite this article: Lee, S. T., Pang, J. N. \& Jawad, Z. A. (2019). Functionalised multiwalled carbon nanotubes/cellulose acetate butyrate mixed matrix membrane for $\mathrm{CO}_{2} / \mathrm{N}_{2}$ separation. J. Phys. Sci., 30(2), 99-135, https://doi.org/10.21315/jps2019.30.2.7

To link to this article: https://doi.org/10.21315/jps2019.30.2.7

\begin{abstract}
The emission of greenhouse gases ( $\mathrm{GHGs}$ ), especially carbon dioxide ( $\left.\mathrm{CO}_{2}\right)$, has been rising indiscriminately causing serious global warming issues. Therefore, to prevent severe consequences of global warming, stern efforts need to be taken to minimise the global GHG emission. One of the most suitable approaches chosen for removal of $\mathrm{CO}_{2}$ is the gas separation membrane technology. The main objective of this work is to synthesise a membrane with good $\mathrm{CO}_{2}$ permeance and $\mathrm{CO}_{2} /$ nitrogen $\left(\mathrm{N}_{2}\right)$ selectivity that can be applied in the industry. Firstly, the cellulose acetate butyrate (CAB) polymer matrix of molecular weight (Mn) 65000 was used to synthesise the membranes with different solvent evaporation times (4 min, $5 \mathrm{~min}$ and $6 \mathrm{~min}$ ) and different solvent exchange drying times (15 min, $30 \mathrm{~min}$ and $60 \mathrm{~min}$ ). Since the performance of the obtained CAB membrane performance was still relatively low $\left(\mathrm{CO}_{2} / \mathrm{N}_{2}\right.$ selectivity of $\left.0.978 \pm 0.011\right)$, the mixed matrix membranes (MMMs) were introduced. The MMM was fabricated by using 4 wt\% of CAB polymer of molecular weight (Mn) 65000 and 0.1 wt\% of functionalised multi-walled carbon nanotubes (MWCNTs-F). In addition, the effect of different MWCNT loadings (0.2 wt\% to $1.2 \mathrm{wt} \%)$ and acetyl contents (12 wt\%-15 wt\% and $28 w t \%-31 \mathrm{wt} \%)$ on $\mathrm{CO}_{2} / \mathrm{N}_{2}$ separation were also investigated. The results proved that the MMM prepared from the CAB polymer of Mn 65000 and $0.1 \mathrm{wt} \%$ of MWCNTs with higher acetyl content, i.e., from $28 \mathrm{wt} \%$ to $31 \mathrm{wt} \%$ had better performance in terms of $\mathrm{CO}_{2} / \mathrm{N}_{2}$ selectivity $(2.887 \pm 0.068)$.
\end{abstract}

Keywords: Acetyl content, cellulose acetate butyrate, mixed matrix membrane, molecular weight, solvent evaporation time 


\section{INTRODUCTION}

According to the International Energy Agency, in 2016 the global carbon dioxide $\left(\mathrm{CO}_{2}\right)$ emission was 32.1 gigatonnes, which is $60 \%$ above emissions since the reference year in the Kyoto Protocol $1990 .{ }^{1}$ The acceleration of economic growth is partly responsible for today's expanding demand for energy. The increased use of fuels, especially conventional fossil fuels that has developed into an indispensable energy source is an undeniable consequence since the industrial revolution. Therefore, the use of a large number of fossil fuels has evolved and became a matter of concern due to their unfavourable effects on the environment, especially the emission of $\mathrm{CO}_{2}{ }^{2,3}$ Hence, some initiatives have been taken to reduce the release of $\mathrm{CO}_{2}$ into the atmosphere. ${ }^{4}$

The membrane separation process is one of the ways to aid the removal of $\mathrm{CO}_{2}$ from the environment. ${ }^{5,6}$ It consists of a composite polymer membrane with a thin selective layer that bonds to a thicker, non-selective and low-cost layer, which gives mechanical support to the membrane. The favoured gases such as $\mathrm{CO}_{2}$ are allowed to pass through the membranes, and at the same time eliminate the other components of the flue gas passing through. Although there is significant advancement in the gas separation membrane systems, there is still a great deal of potential to be realised in this technology. ${ }^{2}$ The main deficiency that takes place in the gas separation membrane technology is the trade-off relationship between the membrane's permeability and selectivity that wards off this technology from attaining the preferred outcome. ${ }^{7}$

Although there have been successful studies of gas separation using the cellulose acetate (CA) membrane, there has not yet been any detailed study on the use of the cellulose acetate butyrate $(\mathrm{CAB})$ polymer matrix for gas separation membrane. ${ }^{2}$ However, an extended study was carried out by Minhas et al. to explore the possibility of the improvement of the $\mathrm{CO}_{2} / \mathrm{N}_{2}$ separation performance by the $\mathrm{CAB}$ polymer matrix. ${ }^{8}$ Currently, the processing parameters, particularly the solvent evaporation time and solvent exchange drying time, are yet to be optimised. ${ }^{9}$

The manipulation of the solvent evaporation time before immersion of the membrane during the coagulation step would affect the surface skin-layer thickness. By altering the solvent evaporation time, different membrane morphologies in terms of porosity and macrovoid substructure and skin layer would be formed. ${ }^{10}$ Paulsen et al. expressed that the duration of evaporation had strong effect on the formation of macrovoids via its effect on the solvent concentration gradient and viscosity of the solution at the instance of immersion into the precipitation bath. ${ }^{11}$ They concluded that macrovoids could be suppressed when the evaporation time was sufficient for the coagulation bath, which caused appropriate 
solidification of the casting solution to prevent the macrovoid formation. Thus, the optimum solvent evaporation time needs to be determined when synthesising a superior $\mathrm{CAB}$ membrane.

On the other hand, water molecules usually occupy the porous substructure during the formation of the membrane due to its asymmetric structure. ${ }^{12}$ With regards to the solvent exchange drying method, water molecules in the membrane will be replaced by 2 -isopropyl alcohol and n-hexane solvents. ${ }^{13}$ Prolonged solvent exchange drying time might damage the structure during the drying process. Therefore, it is essential to determine the optimum solvent evaporation time and exchange drying time to synthesise a superior $\mathrm{CAB}$ membrane.

Besides, it has been realised that the separation performance of the polymeric membranes has constraints, which is the trade-off relationship between $\mathrm{CO}_{2}$ and $\mathrm{N}_{2}$ permeability with selectivity. ${ }^{14}$ Thus, the gas separation performance of the membrane can be optimised by synthesising a mixed matrix membranes (MMM), which consists of the $\mathrm{CAB}$ polymer and the functionalised multi-walled carbon nanotubes (MWCNTs) to optimise the membrane performance. This type of membrane combines the processing feasibility from the polymeric material and superior gas separation performance of inorganic material, which eventually improves the gas separation performance. A previous work reported that the use of the MWCNTs as fillers had the effect of improving the MMMs. For example, Kim et al. prepared the poly(imide siloxane) membrane with the MWCNTs and found that the additional MWCNTs increased the permeability of gases such as oxygen $\left(\mathrm{O}_{2}\right)$, methane $\left(\mathrm{CH}_{4}\right)$ and nitrogen $\left(\mathrm{N}_{2}\right){ }^{15}$ Unfortunately, a weak surface interaction existed between the inorganic fillers and the polymer matrix, resulting in the selectivity to decrease..$^{16}$ To overcome this weakness and to improve the gas separation performance of MMM, this study investigated the different MWCNT loadings and acetyl contents on gas separation performances.

Therefore, the main objective of this work is to optimise the solvent evaporation time and solvent exchange drying time when synthesising a $\mathrm{CAB}$ membrane with high separation performance. Besides, a high performance MMM (CABMWCNTs) with different acetyl content is synthesised for $\mathrm{CO}_{2} / \mathrm{N}_{2}$ separation. Up to date, no studies have ever been conducted on the effects of solvent evaporation time and solvent exchange drying duration when fabricating a high performing CAB membrane with molecular weight (Mn) of 65000 for $\mathrm{CO}_{2}$ and $\mathrm{N}_{2}$ separation. 


\section{EXPERIMENTAL}

\subsection{Chemicals and Reagents}

Chemicals and reagents used in this research study are listed in Table 1, as shown below:

Table 1: List of the chemicals and reagents used.

\begin{tabular}{|c|c|c|c|}
\hline Chemicals & Characteristics & Supplier & Purpose \\
\hline CAB polymer & $\begin{array}{l}\mathrm{Mn}=65000 \\
(\text { Acetyl content }=28 \\
\text { wt } \%-31 \mathrm{wt} \%)\end{array}$ & $\begin{array}{l}\text { Sigma-Aldrich, } \\
\text { Malaysia }\end{array}$ & $\begin{array}{l}\text { Polymer for } \\
\text { membrane synthesis }\end{array}$ \\
\hline CAB polymer & $\begin{array}{l}\mathrm{Mn}=70000 \\
(\text { Acetyl content }=12 \\
\mathrm{wt} \%-15 \mathrm{wt} \%) \\
\mathrm{Mn}=70000\end{array}$ & $\begin{array}{l}\text { Sigma-Aldrich, } \\
\text { Malaysia }\end{array}$ & $\begin{array}{l}\text { Polymer for } \\
\text { membrane synthesis }\end{array}$ \\
\hline Acetone & ACS reagent $99.8 \%$ purity & Merck, Malaysia & $\begin{array}{l}\text { Solvent for membrane } \\
\text { synthesis }\end{array}$ \\
\hline Ethanol & ACS reagent $99.8 \%$ purity & Merck, Malaysia & $\begin{array}{l}\text { MWCNT } \\
\text { functionalisation }\end{array}$ \\
\hline $\begin{array}{l}\text { Beta- } \\
\text { cyclodextrin } \\
(\beta-C D)\end{array}$ & ACS reagent $99.8 \%$ purity & Merck, Malaysia & $\begin{array}{l}\text { MWCNT } \\
\text { functionalisation }\end{array}$ \\
\hline Chloroform & ACS reagent $99.8 \%$ purity & Merck, Malaysia & $\begin{array}{l}\text { Solvent for membrane } \\
\text { synthesis }\end{array}$ \\
\hline MWCNTs & $\begin{array}{l}95 \% \text { purity } \\
D_{i}=8.85 \mathrm{~nm} \\
D_{o}=26.62 n m\end{array}$ & $\begin{array}{l}\text { Shenzhen Nanotech } \\
\text { Port Co. Ltd., China }\end{array}$ & $\begin{array}{l}\text { Inorganic fillers for } \\
\text { membrane synthesis }\end{array}$ \\
\hline $\begin{array}{l}\text { 2-isopropyl } \\
\text { alcohol }\end{array}$ & ACS reagent $99.8 \%$ purity & Merck, Malaysia & Membrane drying \\
\hline n-hexane & ACS reagent $99.8 \%$ purity & Merck, Malaysia & Membrane drying \\
\hline $\mathrm{CO}_{2}$ & Purified cylinder & $\begin{array}{l}\text { Eastern Oxygen } \\
\text { Industries Sdn. Bhd., } \\
\text { Malaysia }\end{array}$ & $\begin{array}{l}\text { Gas for separation } \\
\text { performance test }\end{array}$ \\
\hline $\mathrm{N}_{2}$ & Purified cylinder & $\begin{array}{l}\text { Eastern Oxygen } \\
\text { Industries Sdn. Bhd., } \\
\text { Malaysia }\end{array}$ & $\begin{array}{l}\text { Gas for separation } \\
\text { performance test }\end{array}$ \\
\hline
\end{tabular}




\subsection{Synthesis of CAB Membrane}

Firstly, a solution consisting of $4 \mathrm{wt} \%$ of $\mathrm{CAB}$ and $96 \mathrm{wt} \%$ of chloroform was prepared and stirred for $24 \mathrm{~h}$ by using the magnetic stirrer until the $\mathrm{CAB}$ was completely dissolved at ambient temperature. ${ }^{17}$ After stirring, the solution was sent for ultrasonic degassing for 20 min to eliminate the existing air bubbles. Next, by using an automatic film applicator the membrane was cast with a casting thickness of $250 \mu \mathrm{m}$. Then, the solvent was allowed to be evaporated for 4 min to remove the remaining excess solvent from the cast membrane followed by immersion into the distilled water for $24 \mathrm{~h} .{ }^{8,18} \mathrm{Next}$, the membrane was dried by immersing it for $60 \mathrm{~min}$ each into 2-isopropyl alcohol and n-hexane solvents, respectively for $60 \mathrm{~min}$ in each solvent. Last but not least, the fabricated CAB membrane was placed in between two glass plates for $24 \mathrm{~h}$ and stored before use. ${ }^{8}$

\subsection{Effect of Solvent Evaporation Time}

The CAB membranes were prepared based on the procedure in Section 2.1 except for the evaporation time ranges that were studied, which were from $4 \mathrm{~min}$ to $6 \mathrm{~min}$. This is presented in Table 2 .

Table 2: Membrane samples with its evaporation time.

\begin{tabular}{lcccccc}
\hline $\begin{array}{l}\text { Membrane } \\
\text { sample }\end{array}$ & $\begin{array}{c}\text { CAB } \\
\text { polymer } \\
\text { conc. } \\
(\text { wt\%) }\end{array}$ & $\begin{array}{c}\text { Solvent } \\
\text { conc. } \\
\text { (wt\%) }\end{array}$ & $\begin{array}{c}\text { Solvent } \\
\text { evaporation } \\
\text { time (min) }\end{array}$ & $\begin{array}{c}\text { Solvent } \\
\text { exchange } \\
\text { drying time } \\
\text { of 2-isopropyl } \\
(\mathrm{min})\end{array}$ & $\begin{array}{c}\text { Solvent } \\
\text { exchange } \\
\text { drying time } \\
\text { of n-hexane } \\
(\mathrm{min})\end{array}$ & $\begin{array}{c}\text { Membrane } \\
\text { casting } \\
\text { thickness } \\
(\mu \mathrm{m})\end{array}$ \\
\hline M1 & 4 & 96 & 4 & 60 & 60 & 250 \\
M2 & 4 & 96 & 5 & 60 & 60 & 250 \\
M3 & 4 & 96 & 6 & 60 & 60 & 250 \\
\hline
\end{tabular}

\subsection{Effect of 2-isopropyl Alcohol Exchange Drying Time}

The $\mathrm{CAB}$ membranes were synthesised by changing the immersion time into 2-isopropyl alcohol from $15 \mathrm{~min}$ to $60 \mathrm{~min}$. This is tabulated in Table 3. 
Table 3: Membrane samples with varying solvent exchange drying time of 2-isopropyl alcohol.

\begin{tabular}{lcccccc}
\hline $\begin{array}{l}\text { Membrane } \\
\text { sample }\end{array}$ & $\begin{array}{c}\text { CAB } \\
\text { polymer } \\
\text { conc. } \\
(\text { wt\%) }\end{array}$ & $\begin{array}{c}\text { Solvent } \\
\text { conc. } \\
(\text { wt\%) }\end{array}$ & $\begin{array}{c}\text { Solvent } \\
\text { evaporation } \\
\text { time (min) }\end{array}$ & $\begin{array}{c}\text { Solvent } \\
\text { exchange } \\
\text { drying time } \\
\text { of 2-isopropyl } \\
(\text { min })\end{array}$ & $\begin{array}{c}\text { Solvent } \\
\text { exchange } \\
\text { drying time } \\
\text { of n-hexane } \\
(\mathrm{min})\end{array}$ & $\begin{array}{c}\text { Membrane } \\
\text { casting } \\
\text { thickness } \\
(\mu \mathrm{m})\end{array}$ \\
\hline M4 & 4 & 96 & 5 & 15 & 60 & 250 \\
M5 & 4 & 96 & 5 & 30 & 60 & 250 \\
M2 & 4 & 96 & 5 & 60 & 60 & 250 \\
\hline
\end{tabular}

\subsection{Effect of n-hexane Exchange Drying Time}

The $\mathrm{CAB}$ membranes were firstly immersed into 2-isopropyl alcohol with optimum 2-isopropyl alcohol exchange drying time of $30 \mathrm{~min}$ before immersing into n-hexane with a time ranges from $15 \mathrm{~min}$ to $60 \mathrm{~min}$ for each sample. Table 4 shows the list of various exchange drying times of $n$-hexane for the CAB membranes dried by using the solvent exchange drying method.

Table 4: Membrane samples with varying solvent exchange drying time of n-hexane.

\begin{tabular}{lcccccc}
\hline $\begin{array}{l}\text { Membrane } \\
\text { sample }\end{array}$ & $\begin{array}{c}\text { CAB } \\
\text { polymer } \\
\text { conc. (wt\%) }\end{array}$ & $\begin{array}{c}\text { Solvent } \\
\text { conc. } \\
(\text { wt\%) }\end{array}$ & $\begin{array}{c}\text { Solvent } \\
\text { evaporation } \\
\text { time (min) }\end{array}$ & $\begin{array}{c}\text { Solvent } \\
\text { exchange } \\
\text { drying time } \\
\text { of 2-isopropyl } \\
(\text { min) }\end{array}$ & $\begin{array}{c}\text { Solvent } \\
\text { exchange } \\
\text { drying time } \\
\text { of n-hexane } \\
(\text { min) }\end{array}$ & $\begin{array}{c}\text { Membrane } \\
\text { casting } \\
\text { thickness } \\
(\mu \mathrm{m})\end{array}$ \\
\hline M6 & 4 & 96 & 5 & 30 & 15 & 250 \\
M7 & 4 & 96 & 5 & 30 & 30 & 250 \\
M5 & 4 & 96 & 5 & 30 & 60 & 250 \\
\hline
\end{tabular}

\subsection{MWCNTs-F}

For removal of moisture content, the MWCNTs were dried for $24 \mathrm{~h}$ in an oven at temperature $120^{\circ} \mathrm{C}$. Next, the dried MWCNTs were functionalised with $\beta$-cyclodextrin ( $\beta-C D)$ by using the soft-cutting approach. ${ }^{19}$ The MWCNTs and $\beta-C D$ were prepared at a concentration ratio of $1: 30 \mathrm{wt} \%$ in accordance to this functionalisation technique. After that, the mixture was grounded with an agate mortar and pestle for 10 min while constantly adding ethanol to achieve a greyish viscous mixture. This mixture was continued to be further grounded for another $2.5 \mathrm{~h}$ until it became a fine grey powder. Lastly, the MWCNTs were heated in an oven for another $24 \mathrm{~h}$ at a temperature of $80^{\circ} \mathrm{C} .{ }^{20}$ 


\subsection{Synthesis of MMMs (CAB-MWCNTs)}

A suspension consisting of MWCNTs and chloroform was prepared and stirred for $4 \mathrm{~h}$ at $750 \mathrm{rpm}$. For better particle distribution, a mechanical stirrer was used. After that, the $\mathrm{CAB}$ was added slowly into the suspension and stirred for $24 \mathrm{~h}$ at $350 \mathrm{rpm} .{ }^{18}$ Thereafter, the casting solution was sonicated for $20 \mathrm{~min}$ to remove the gas bubbles. ${ }^{17} \mathrm{~A} 250 \mu \mathrm{m}$ film thickness was cast using the automatic film applicator. The chloroform was allowed to evaporate from the film for $5 \mathrm{~min}$. The film was later immersed into the distilled water overnight to remove the chloroform. The membrane was subsequently immersed into 2-isopropyl alcohol and n-hexane for $30 \mathrm{~min}$ each, respectively. Lastly, the fabricated MMMs were placed between two glass plates with filter papers for $24 \mathrm{~h}$ and stored before use. The compositions of the MMMs fabrication used in this research study were determined using Equation 1 and Equation $2 .{ }^{20}$ The compositions of the fabricated MMMs are also tabulated in Table 5.

$$
\text { Solid base MWCNTs }=\frac{\left(\frac{\text { Total Filler }}{100}\right) \times \text { CAB }}{\left[1-\frac{\text { Total Filler }}{100} \times(1+30)\right]}
$$

where total filler $=$ embedded MWCNTs into CAB polymer.

$$
\text { Solid base of } \beta-\mathrm{CD}=30 \times \text { Solid Base MWCNTs }
$$

Table 5: Compositions of MMM fabrication.

\begin{tabular}{lcccccc}
\hline & & & & & \multicolumn{3}{c}{ MWCNTs } \\
\cline { 5 - 7 } $\begin{array}{l}\text { Membrane } \\
\text { sample }\end{array}$ & $\begin{array}{c}\text { Molecular } \\
\text { weight } \\
(\mathrm{Mn})\end{array}$ & $\begin{array}{c}\text { CAB } \\
\text { polymer } \\
(\mathrm{wt} \%)\end{array}$ & $\begin{array}{c}\text { Solvent } \\
\text { concentration } \\
(\mathrm{wt} \%)\end{array}$ & $\begin{array}{c}\text { Total filler } \\
(\mathrm{wt} \%)\end{array}$ & $\begin{array}{c}\text { Solid base } \\
\text { MWCNTs } \\
(\mathrm{wt} \%)\end{array}$ & $\begin{array}{c}\text { Solid base } \\
\text { B-CD } \\
(\mathrm{wt} \%)\end{array}$ \\
\hline MMM-0.1F & 65000 & 4 & 96.00 & 0.1 & 0.010 & 0.300 \\
MMM-0.2F & 70000 & 4 & 95.74 & 0.2 & 0.008 & 0.255 \\
MMM-0.7F & 70000 & 4 & 94.89 & 0.7 & 0.036 & 1.074 \\
MMM-0.7F & 65000 & 4 & 94.89 & 0.7 & 0.036 & 1.074 \\
MMM-0.7F & 12000 & 4 & 94.89 & 0.7 & 0.036 & 1.074 \\
MMM-1.0F & 70000 & 4 & 94.20 & 1.0 & 0.058 & 1.739 \\
MMM-1.2F & 70000 & 4 & 93.63 & 1.2 & 0.076 & 2.293 \\
MMM-1.7F & 70000 & 4 & 91.54 & 1.7 & 0.144 & 4.314 \\
MMM-2.5F & 70000 & 4 & 82.22 & 2.5 & 0.444 & 13.332 \\
\hline
\end{tabular}




\subsection{Single Gas Permeation Test}

The test for single gas permeation was conducted using the procedure published in a previous work. ${ }^{18}$ The membrane permeance calculation was determined by using Equation 3, which is also known as pressure normalised flux, and is expressed in GPU. ${ }^{7,18}$ The ideal separation factor $\alpha_{i / j}$ for $\mathrm{CO}_{2} / \mathrm{N}_{2}$ was approximated by using Equation 4.,21

$$
\frac{\mathrm{P}}{1}=\frac{\mathrm{Q}}{\mathrm{A} \Delta \mathrm{p}}
$$

where,

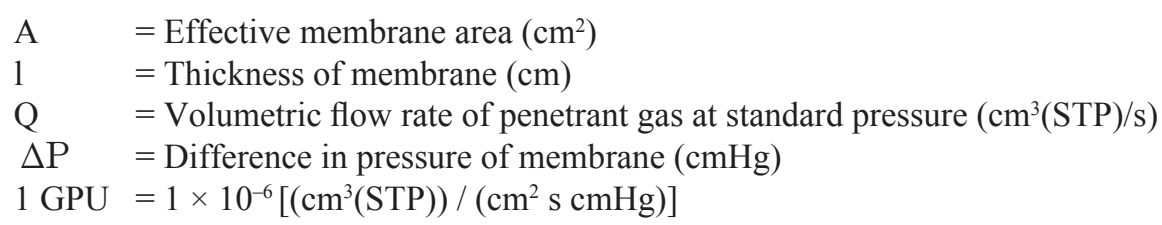

$$
\alpha_{\mathrm{CO}_{2} \mathrm{~N}_{2}}=\frac{\mathrm{P}_{\mathrm{CO}_{2}}}{\mathrm{P}_{\mathrm{N}_{2}}}=\frac{\left(\frac{\mathrm{P}}{1}\right) \mathrm{CO}_{2}}{\left(\frac{\mathrm{P}}{1}\right) \mathrm{N}_{2}}
$$

where $\mathrm{P}_{\mathrm{CO}_{2}}$ and $\mathrm{P}_{\mathrm{N} 2}$ are permeabilities of $\mathrm{CO}_{2}$ and $\mathrm{N}_{2}$ respectively.

A minimum of three specimens were needed to be tested for each sample. The average values together with its standard errors were calculated and recorded. To ensure that the $\mathrm{CO}_{2}$ gas was removed entirely from the fabricated CAB membrane, the system was flushed by using pure $\mathrm{N}_{2}$ gas for approximately $15 \mathrm{~min}$ before replacing the gas. ${ }^{18}$

\subsection{SEM}

The morphology and cross-section of the synthesised membrane was characterised using the scanning electron microscope (SEM, Hitachi TM3000, Tokyo, Japan). The SEM scans a focused electron beam over a surface to produce an image. The electrons in the beam then interact with the sample, and generate various signals that can be used to obtain the relevant information. ${ }^{22}$ All the membrane samples were required to be kept overnight in the cryogenic freezer at $-80^{\circ}$. The membrane samples were then cut into small pieces. To observe the surface and cross-sections of the membrane these fractured samples were later coated with platinum sputtering. 


\subsection{Attenuated Total Reflectance Fourier Transform Infrared Spectroscopy (ATR-FTIR)}

The Thermo Scientific FTIR spectrometer (NICOLET iS10, United States) with wavelength ranging from $600 \mathrm{~cm}^{-1}$ to $4000 \mathrm{~cm}^{-1}$ was used to characterise the functional groups in the synthesised membrane. A diamond crystal was used to obtain each spectrum from 32 scans with wavelength of $4 \mathrm{~cm}^{-1}$ and an incident angle of 45 .

\section{RESULTS AND DISCUSSSION}

\subsection{Effect of Solvent Evaporation Time}

\subsubsection{Membrane characterisation}

Figure 1 exhibits the corresponding membrane surface and cross-sectional morphology of the $\mathrm{CAB}$ membranes fabricated with the solvent evaporation times of $4 \mathrm{~min}$ (M1), $5 \mathrm{~min}(\mathrm{M} 2)$ and $6 \mathrm{~min}$ (M3). Figure 1(a, c, e) shows that the membrane surfaces of M1, M2 and M3 are nearly smooth and defect-free. This is because the compatible membrane combination, causes the surface of the membrane to become closely packed.

Based on Figure 1(b, d, f), the thickness of M1 (4 min), M2 (5 min) and M3 (6 $\mathrm{min}$ ) are $9.27 \pm 0.013 \mu \mathrm{m}, 9.55 \pm 0.014 \mu \mathrm{m}$ and $13.24 \pm 0.013 \mu \mathrm{m}$, respectively. This is due to the prolonged evaporation time of chloroform, which is highly volatile whilst escaping, and the settling down of water vapour from the atmosphere into the membrane instigating expansion in the membrane volume. ${ }^{23}$ 

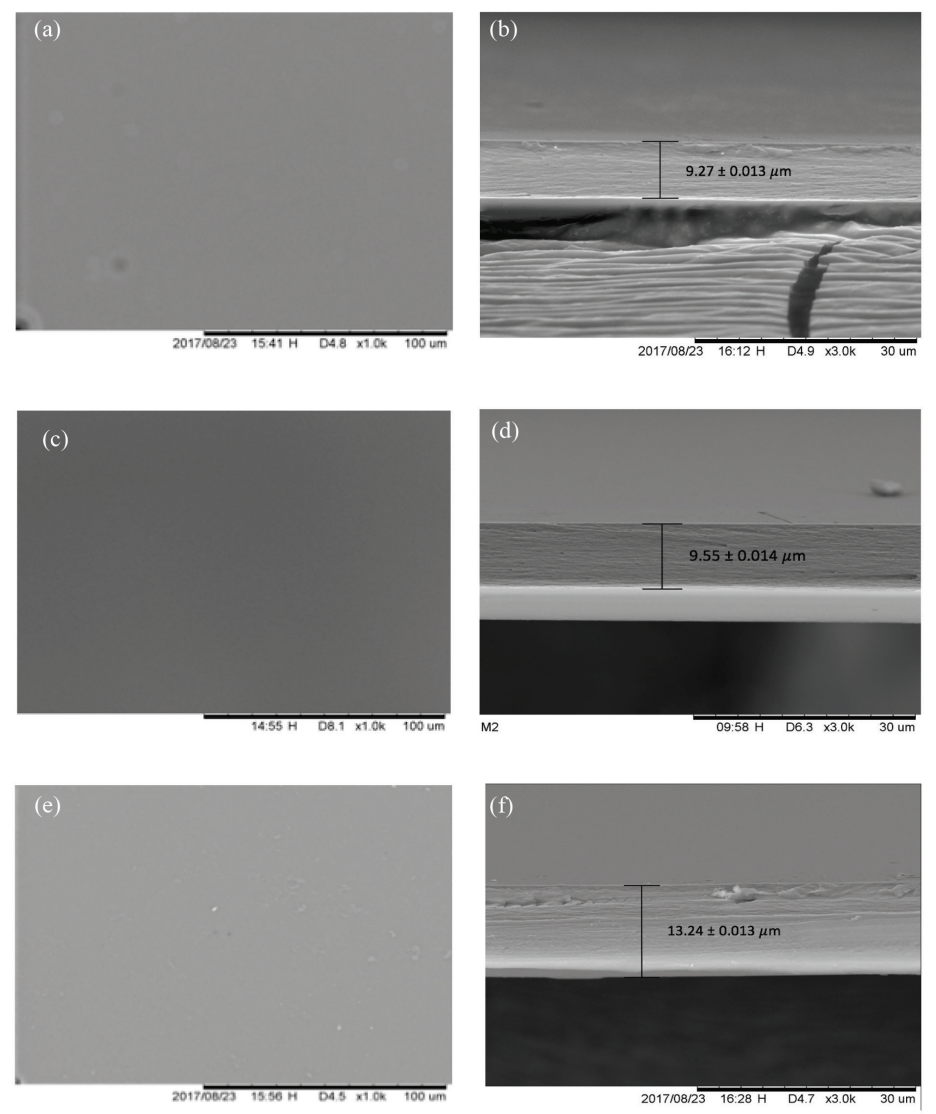

Figure 1: SEM micrographs of membrane surface and cross-sectional structure synthesised with different solvent evaporation times of (a, b) $4 \mathrm{~min}$ (M1), (c, d) $5 \mathrm{~min}$ (M2) and (e, f) 6 min (M3), with casting thickness of $250 \mu \mathrm{m}, 4$ $\mathrm{wt} \%$ of $\mathrm{CAB}$ polymer concentration, and solvent exchange drying time of 60 min each for 2-isopropyl alcohol and n-hexane.

\subsubsection{Separation Performance of the Membranes}

The separation performances of M1 (4 min), M2 (5 min) and M6 (6 min) were carried out by using the single gas permeation test. The results of the $\mathrm{CO}_{2}$ permeance for M1, M2 and M3 are shown in Figure 2. As observed from this Figure, M2 has the highest $\mathrm{CO}_{2}$ permeance, which is $205.093 \pm 1.225 \mathrm{GPU}$, while M1 and M3 are $220.312 \pm 0.345$ GPU and $160.368 \pm 0.327$ GPU, respectively. 


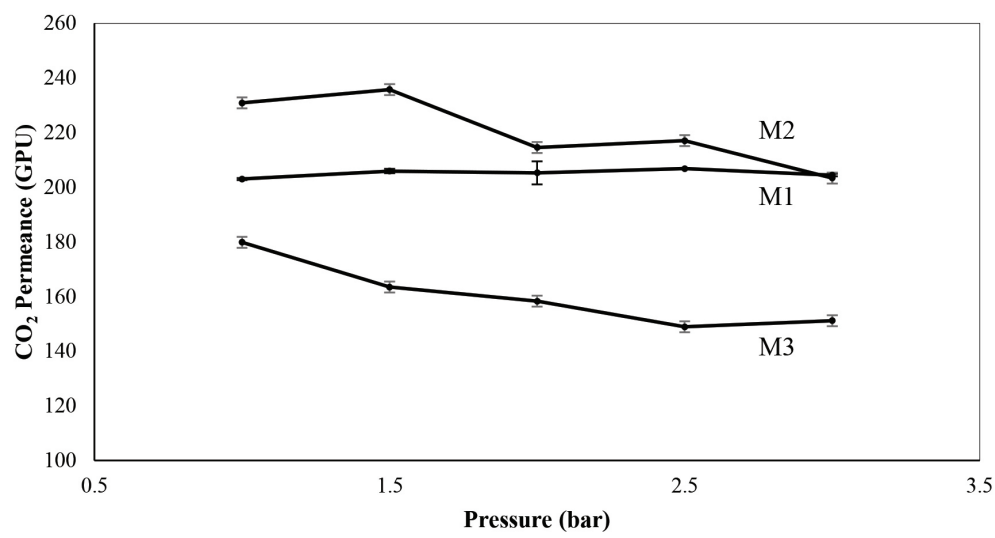

Figure 2: $\mathrm{CO}_{2}$ permeance for $\mathrm{CAB}$ membrane fabricated with different solvent evaporation times of 4 min (M1), 5 min (M2) and 6 min (M3) with casting thickness of $250 \mu \mathrm{m}$, polymer concentration of $4 \mathrm{wt} \%$, and solvent exchange drying time of $60 \mathrm{~min}$ each for 2-isopropyl alcohol and n-hexane.

Moreover, as observed in Figure 3, M2 also obtained the highest $\mathrm{N}_{2}$ permeance result of $249.339 \pm 0.569 \mathrm{GPU}$, while the $\mathrm{N}_{2}$ permeance of $\mathrm{M} 1$ and $\mathrm{M} 3$ are 228.864 $\pm 1.275 \mathrm{GPU}$ and $192.028 \pm 0.783 \mathrm{GPU}$, respectively.

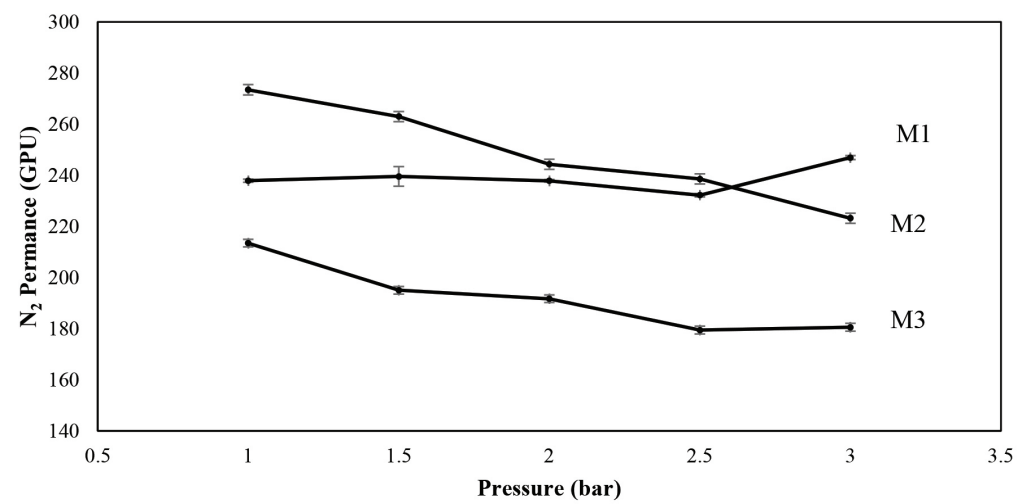

Figure 3: $\mathrm{N}_{2}$ permeance for $\mathrm{CAB}$ membrane with different solvent evaporation times of 4 min (M1), 5 min (M2) and 6 min (M3), with casting thickness of $250 \mu \mathrm{m}$, polymer concentration of $4 \mathrm{wt} \%$, and solvent exchange drying time of $60 \mathrm{~min}$ each for 2-isopropyl alcohol and n-hexane.

This is due to the high intensity of the functional groups of the CAB membrane prepared with a $\mathrm{CAB}$ polymer concentration of $4 \mathrm{wt} \%$, casting thickness of $250 \mu \mathrm{m}, 5 \mathrm{~min}$ evaporation time, as well as $60 \mathrm{~min}$ each for 2-isopropyl alcohol 
and n-hexane exchange drying time (M2) as compared to M1 (4 min) and M3 (6 min). This is presented in Figure 4. The spectrum obtained for M2 demonstrates the highest transmittance band at $1219.26 \mathrm{~cm}^{-1}$ and $1162.94 \mathrm{~cm}^{-1}$, which indicates the $\mathrm{C}-\mathrm{O}$ group of the $\mathrm{CAB}$ membrane. Next, there is a strong stretching vibration at $1736.11 \mathrm{~cm}^{-1}$, which is due to the carbonyl bond of $\mathrm{C}=\mathrm{O}$ group. Besides that, the band at $1366.52 \mathrm{~cm}^{-1}$ and $900.98 \mathrm{~cm}^{-1}$ reveals the presence of the carboxylic acid (C-H) group and alkene (=C-H) group, respectively. ${ }^{24}$ According to Zhang et al., $\mathrm{CO}_{2}$ is considered as one of the gas-responsive polymers where it can interact with the $\mathrm{CAB}$ polymer chains and functional groups that were mentioned previously. ${ }^{25}$ Thus, the $\mathrm{CO}_{2}$ permeance of $\mathrm{M} 2$ is higher than $\mathrm{M} 1$ and $\mathrm{M} 3$.

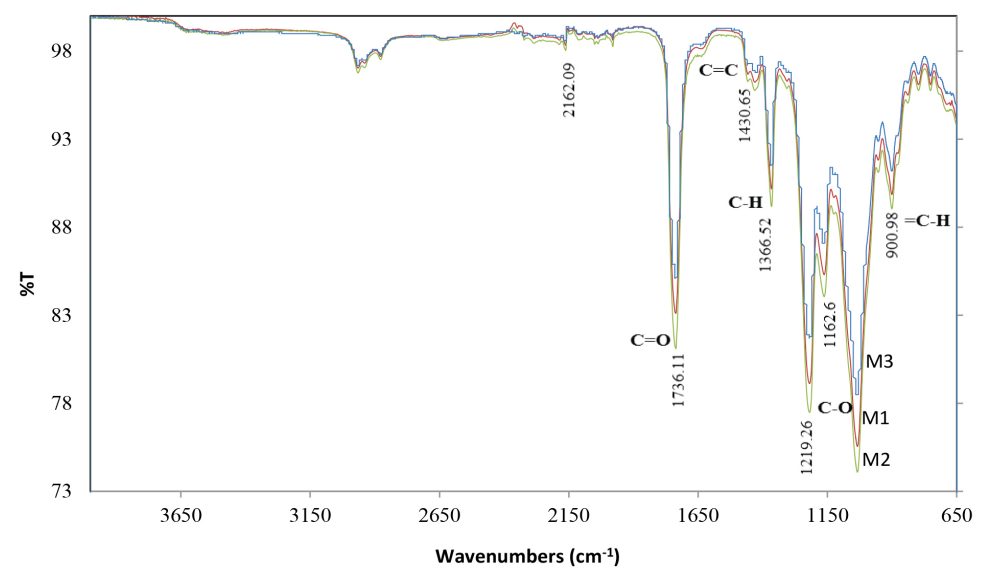

Figure 4: The ATR-FTIR spectra of M1, M2, and M3 with 4 min, 5 min and 6 min solvent evaporation time respectively, and solvent exchange drying time of $60 \mathrm{~min}$ for both 2-isopropyl alcohol and n-hexane.

The $\mathrm{CO}_{2} / \mathrm{N}_{2}$ separation performance for the $\mathrm{CAB}$ membranes with different solvent evaporation times is demonstrated in Figure 5. M2 is observed to have the highest selectivity of $0.885 \pm 0.015$, while M1 and M3 have a selectivity of $0.859 \pm 0.010$ and $0.835 \pm 0.003$, respectively. From the results obtained, when the evaporation time increased from $4 \mathrm{~min}$ to $5 \mathrm{~min}$, the selectivity increased. However, the membrane selectivity reduced when the membrane's solvent evaporation time was further increased from $5 \mathrm{~min}$ to $6 \mathrm{~min}$. This was due to the prolonged evaporation time for the chloroform to escape, which caused water vapour from the atmosphere to settle down on the membrane surface, thus, decreasing the membrane separation performance. ${ }^{26}$ 


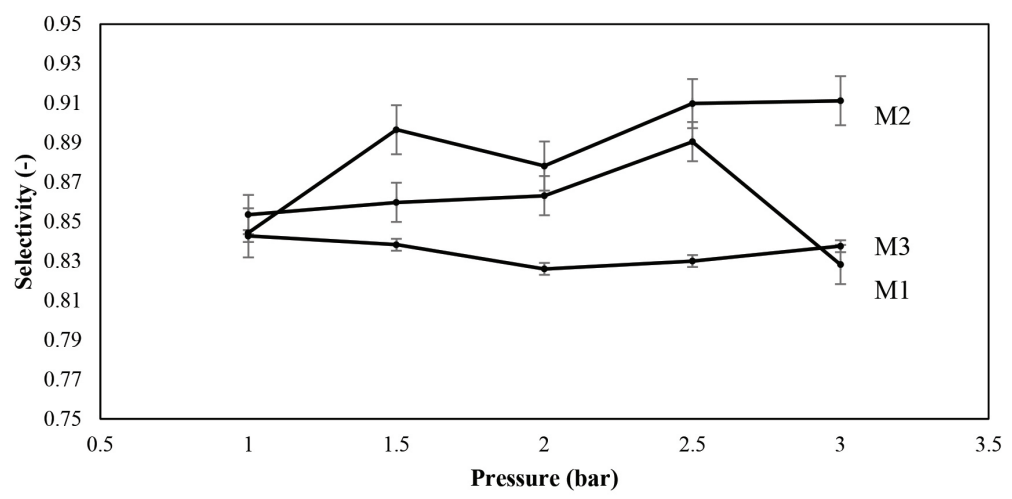

Figure 5: Selectivity of CAB membrane with different solvent evaporation times of $4 \mathrm{~min}$ (M1), 5 min (M2) and 6 min (M3) with casting thickness of $250 \mu \mathrm{m}$, polymer concentration of $4 \mathrm{wt} \%$, and solvent exchange drying time of $60 \mathrm{~min}$ each for 2-isopropyl alcohol and n-hexane.

In conclusion, the $\mathrm{CAB}$ membrane with solvent evaporation time of 5 min (M2) had the best membrane performance, with the highest $\mathrm{CO}_{2}$ permeance and $\mathrm{CO}_{2} / \mathrm{N}_{2}$ selectivity as compared to M1 (4 min) and M3 (6 min).

\subsection{Effect of 2-isopropyl Alcohol Exchange Drying Time}

\subsubsection{Membrane characterisation}

The physical structure of the synthesised $\mathrm{CAB}$ membrane at different solvent exchange drying times of $15 \mathrm{~min}$ (M4), $30 \mathrm{~min}$ (M5) and $60 \mathrm{~min}$ (M2) of 2-isopropyl alcohol was determined by using the SEM as shown in Figure 6. As seen in Figure 6(a to d), M4 (15 $\mathrm{min})$ and M5 (30 $\mathrm{min})$ proved a smooth surface with membrane thickness of $5.16 \pm 0.024 \mu \mathrm{m}$ and $5.09 \pm 0.013 \mu \mathrm{m}$, respectively. It was observed that when the exchange drying time of 2-isopropyl alcohol exchange drying time increased from $15 \mathrm{~min}$ to $30 \mathrm{~min}$, there was a slight reduction in thickness. This was because there was sufficient exchange time for the removal of water molecules from the $\mathrm{CAB}$ membrane by the 2-isopropyl alcohol solvent. Conversely, the membrane thickness increased considerably to $9.55 \pm 0.014 \mu \mathrm{m}$ when the 2-isopropyl alcohol exchange drying time increased to $60 \mathrm{~min}$ (M2). As explained by Jawad et al., this was due to the excessive exchange drying time of 2-isopropyl alcohol exchange drying leading to the collapse of the membrane structure. $^{12}$ 


\subsubsection{Separation performance of the membranes}

The separation performances of M4 (15 min), M5 (30 min) and M2 (60 min) were evaluated by using the $\mathrm{CO}_{2}$ single gas permeation test. The $\mathrm{CO}_{2}$ permeance results are presented in Figure 7. This figure shows that $\mathrm{M} 5$ has the highest $\mathrm{CO}_{2}$ permeance, which is $274.04 \pm 0.50 \mathrm{GPU}$, while the $\mathrm{CO}_{2}$ permeance of $\mathrm{M} 4$ and $\mathrm{M} 2$ are approximately $230.914 \pm 0.446$ GPU and $205.093 \pm 1.225$ GPU, respectively. When the 2-isopropyl alcohol solvent exchange time increased from $15 \mathrm{~min}$ (M4) to $30 \mathrm{~min}$ (M5), the water content inside the $\mathrm{CAB}$ membrane structure reduced. Eventually, it reduced the interaction with $\mathrm{CO}_{2}$ when it was subjected to a performance test, and thus, increased the $\mathrm{CO}_{2}$ permeance. By further increasing the 2-isopropyl alcohol exchange drying time to $60 \mathrm{~min}(\mathrm{M} 2)$, the $\mathrm{CO}_{2}$ permeance decreased from $274.044 \pm 0.502$ GPU to $205.093 \pm 1.225$ GPU. This is due to the increased thickness of $\mathrm{M} 2$, which has a higher $\mathrm{CO}_{2}$ flow resistance. This is shown in Figure 6(f).

The $\mathrm{N}_{2}$ permeance results for M4 (15 $\left.\mathrm{min}\right)$, M5 (30 $\left.\mathrm{min}\right)$ and M2 $(60 \mathrm{~min})$ are $278.72 \pm 0.807$ GPU, $296.968 \pm 0.847$ GPU and $249.339 \pm 0.569$ GPU, respectively as indicated in Figure 8. In general, a thicker membrane employs a higher flow resistance to the membrane, which results in a lower separation performance of the membrane. As mentioned in Section 3.2.1, the permeance trend follows the thickness of the $\mathrm{CAB}$ membranes as well. The thicker the membrane, the lower the permeance of the membrane. ${ }^{18}$

Figure 9 displays the $\mathrm{CO}_{2} / \mathrm{N}_{2}$ selectivity of the synthesised $\mathrm{CAB}$ membrane with different exchange drying times of 2-isopropyl alcohol. The selectivity of $\mathrm{CO}_{2} / \mathrm{N}_{2}$ increased from $0.829 \pm 0.022$ to $0.923 \pm 0.013$ when the 2-isopropyl alcohol exchange time increased from $15 \mathrm{~min}$ (M4) to $30 \mathrm{~min}$ (M5). This was mainly because there was sufficient time to replace water with 2-isopropyl alcohol for the $\mathrm{CAB}$ membrane. However, when the span membrane was subjected to a longer exchange time of $60 \mathrm{~min}(\mathrm{M} 2)$, the selectivity was reduced to $0.885 \pm$ 0.015 , as the exchange time was prolonged, causing the excessive 2-isopropyl alcohol exchange time. ${ }^{12}$ The prolonged 2-isopropyl alcohol exchange time for the membrane has caused the decrease in the $\mathrm{CAB}$ membrane separation performance. As explained by Jawad et al., this was due to the collapse of the CAB membrane structure (M2) that eventually increased the thickness of M2 to $9.55 \pm 0.014 \mu \mathrm{m} .{ }^{20}$ 

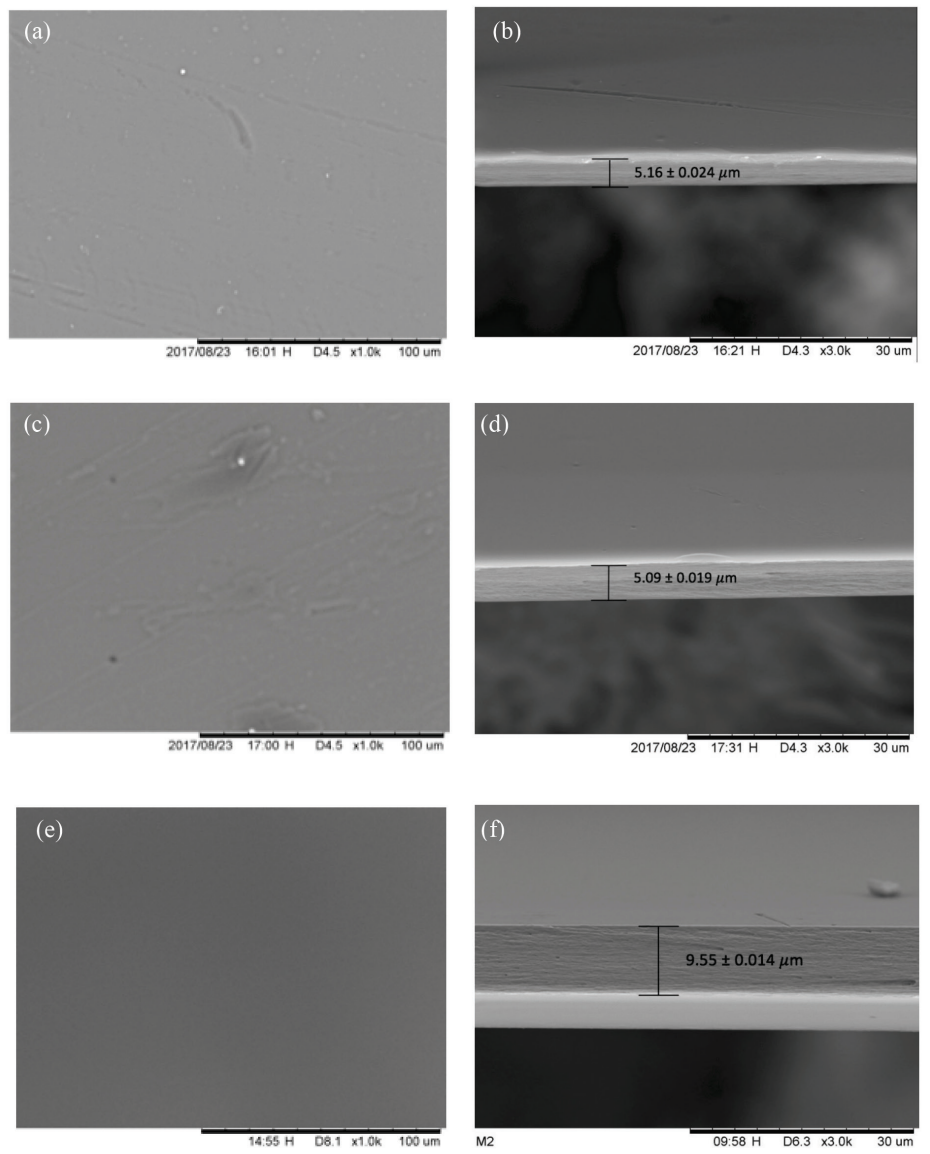

Figure 6: SEM micrographs of membrane surface and cross-sectional structure synthesised with different 2-isopropyl alcohol exchange drying times of $(a, b)$ $15 \mathrm{~min}$ (M4), (c, d) $30 \mathrm{~min}$ (M5), and (e, f) $60 \mathrm{~min}$ (M2), followed by $60 \mathrm{~min}$ of n-hexane exchange drying time, with casting thickness of $250 \mu \mathrm{m}, 4 \mathrm{wt} \%$ of $\mathrm{CAB}$ polymer concentration, and solvent evaporation time of $5 \mathrm{~min}$. 


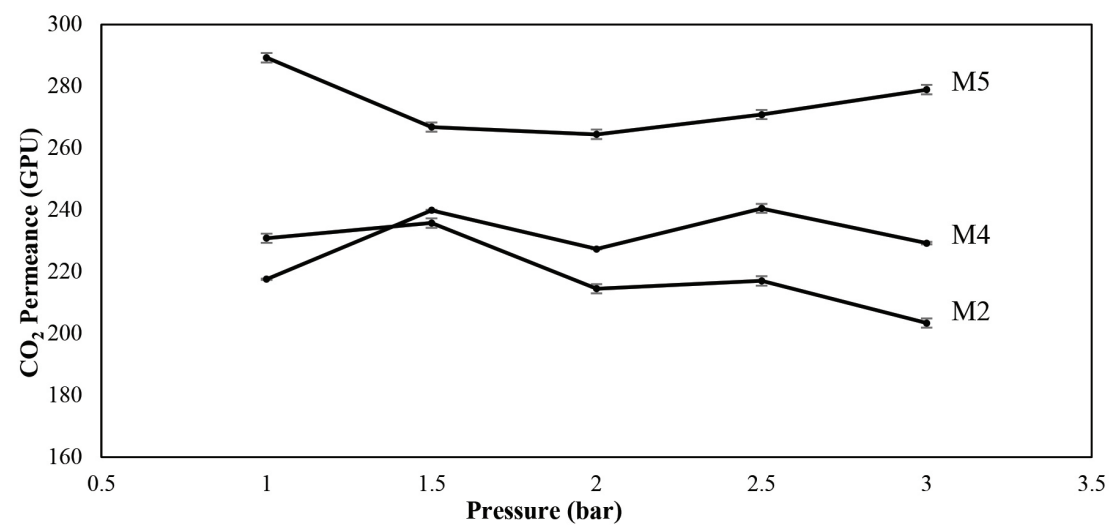

Figure 7: $\mathrm{CO}_{2}$ permeance of $\mathrm{CAB}$ membrane fabricated with different 2-isopropyl alcohol exchange drying times of $15 \mathrm{~min}$ (M4), $30 \mathrm{~min}$ (M5) and $60 \mathrm{~min}$ (M2), followed by $60 \mathrm{~min}$ of $\mathrm{n}$-hexane exchange drying time with casting thickness of $250 \mu \mathrm{m}$, polymer concentration of $4 \mathrm{wt} \%$, and $5 \mathrm{~min}$ of solvent evaporation time.

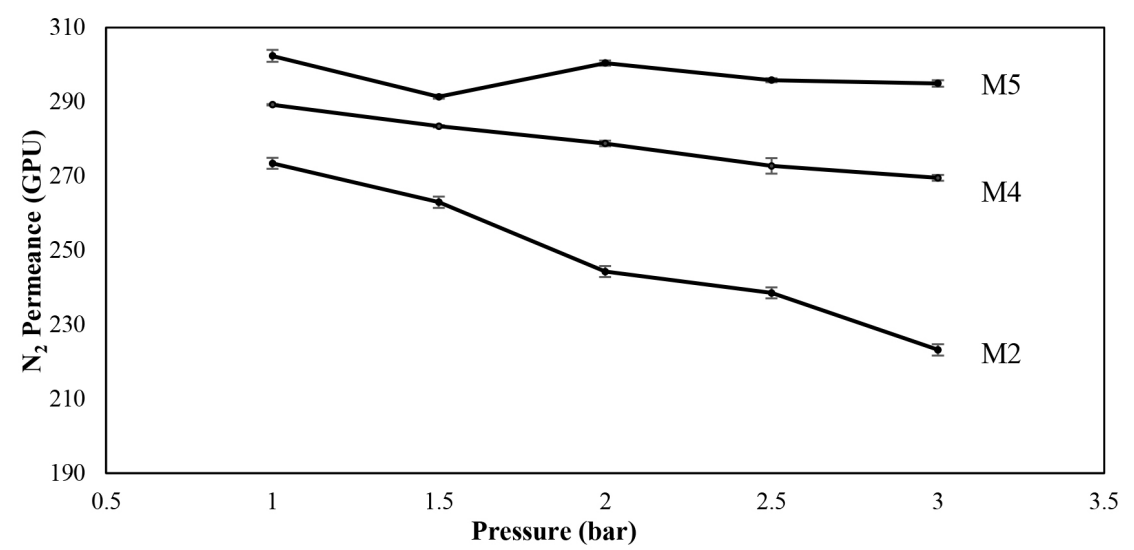

Figure 8: $\mathrm{N}_{2}$ permeance for CAB membrane with different 2-isopropyl alcohol exchange drying times of $15 \mathrm{~min}$ (M4), $30 \mathrm{~min}$ (M5) and $60 \mathrm{~min}$ (M2), followed by $60 \mathrm{~min}$ of $\mathrm{n}$-hexane exchange drying time with casting thickness of $250 \mu \mathrm{m}$, polymer concentration of $4 \mathrm{wt} \%$, and $5 \mathrm{~min}$ of solvent evaporation time. 


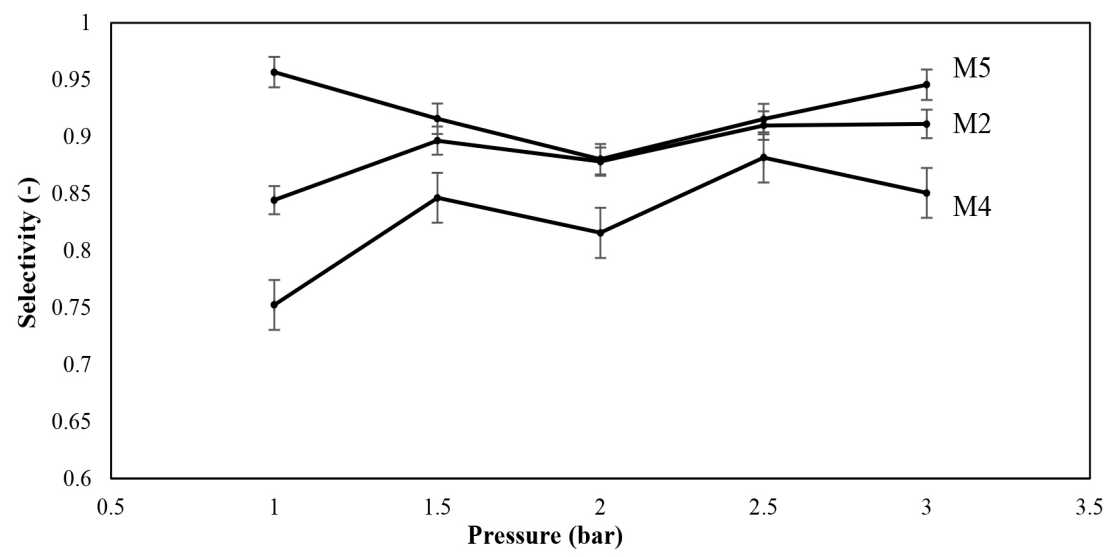

Figure 9: Selectivity of CAB membrane with different 2-isopropyl alcohol exchange drying times of $15 \mathrm{~min}$ (M4), $30 \mathrm{~min}$ (M5) and $60 \mathrm{~min}$ (M2), followed by $60 \mathrm{~min}$ of $\mathrm{n}$-hexane exchange drying time with casting thickness of $250 \mu \mathrm{m}$, polymer concentration of $4 \mathrm{wt} \%$, and $5 \mathrm{~min}$ of solvent evaporation time.

In summary, it was determined that the 2-isopropyl alcohol exchange drying duration of $30 \mathrm{~min}$ had the best membrane performance, with the highest $\mathrm{CO}_{2}$ and $\mathrm{N}_{2}$ permeance and selectivity.

\subsection{Effect of n-hexane Exchange Drying Time}

Based on these results, the solvent exchange drying time of $30 \mathrm{~min}$ of 2-isopropyl alcohol was the best for enhancing the performance of the CAB membrane. Hence, the experiment was carried out to determine the effects of n-hexane drying time.

\subsubsection{Membrane characterisation}

The surface morphology of the $\mathrm{CAB}$ membrane at different n-hexane solvent exchange drying times of $15 \mathrm{~min}$ (M6), $30 \mathrm{~min}$ (M7) and $60 \mathrm{~min}$ (M5) was determined by using the SEM. This is displayed in Figure 10. As observed in Figure 10(a to d), both the M6 and M7 membranes have smooth surfaces and thicknesses of $8.23 \pm 0.041 \mu \mathrm{m}$ and $4.96 \pm 0.020 \mu \mathrm{m}$, respectively. When the exchange drying time of $n$-hexane increased from $15 \mathrm{~min}$ to $30 \mathrm{~min}$, a thinner membrane was obtained. This is due to the membrane having sufficient diffusion time for $n$-hexane to replace the 2-isopropyl alcohol. However, when the n-hexane exchange drying time was further increased to $60 \mathrm{~min}$, the membrane thickness increased from $4.95 \pm 0.020 \mu \mathrm{m}$ to $5.09 \pm 0.013 \mu \mathrm{m}$ as indicated in 
Figure 10(d, f). This occurred because of the excessive n-hexane exchange drying time, which was causing the $\mathrm{CAB}$ structure to change from the original structure of CAB membrane. ${ }^{12}$
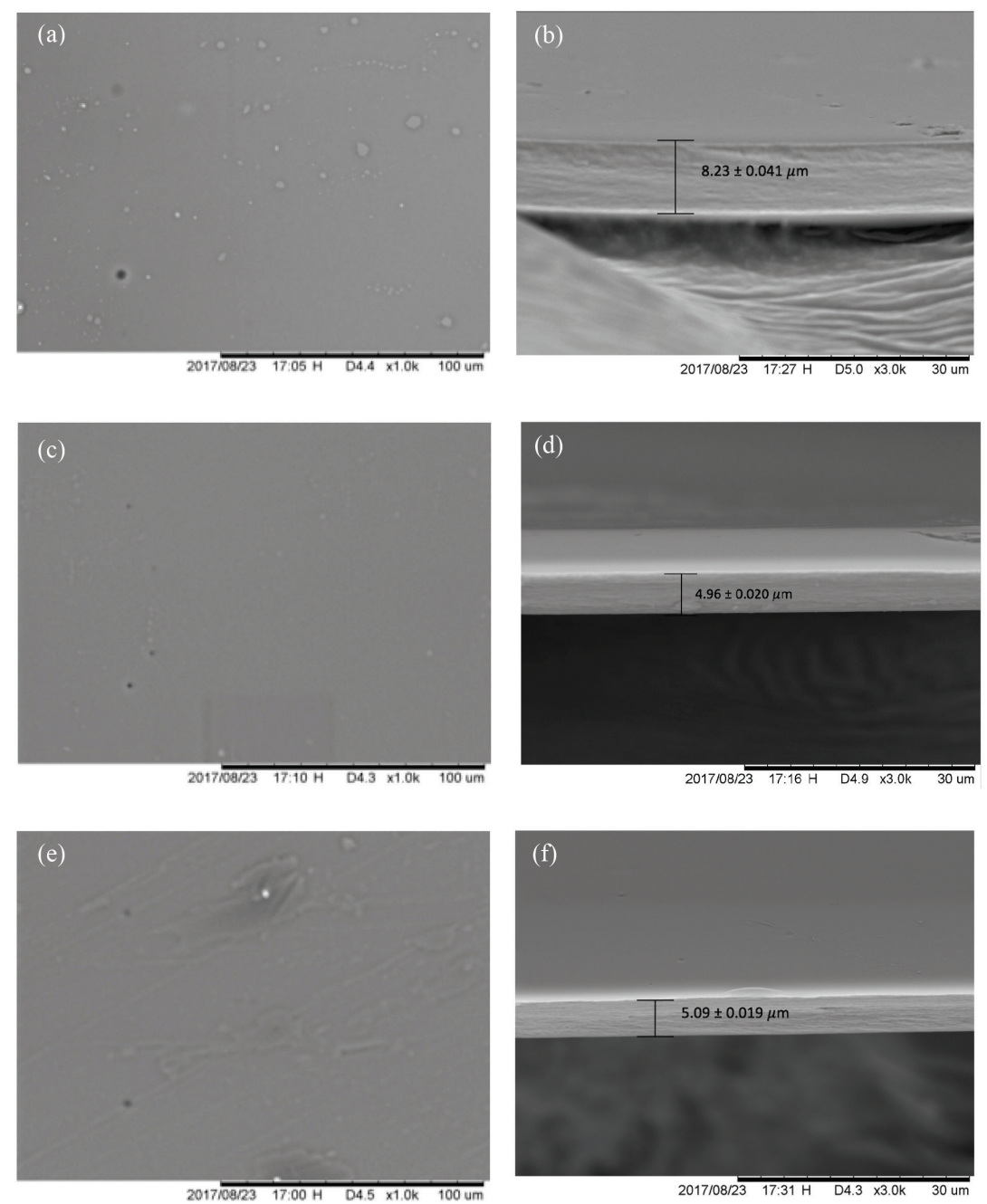

Figure 10: SEM micrographs of membrane surface and cross-sectional structure synthesised with 30 min of 2-isopropyl alcohol, followed by different $n$-hexane exchange drying times of (a, b) 15 min (M6), (c, d) 30 min (M7), and (e, f) 60 min (M5), with casting thickness of $250 \mu \mathrm{m}, 4 \mathrm{wt} \%$ of CAB polymer concentration, and solvent evaporation time of $5 \mathrm{~min}$. 


\subsubsection{Separation performance of the membranes}

The performances of the membranes M6 (15 min), M7 (30 min) and M5 (60 min) were evaluated by using the $\mathrm{CO}_{2}$ and $\mathrm{N}_{2}$ single gas permeation test. As displayed in Figure 11, the highest $\mathrm{CO}_{2}$ permeance is $322.603 \pm 0.467 \mathrm{GPU}$, while the $\mathrm{CO}_{2}$ permeance for M6 and M5 are 218.096 $\pm 0.781 \mathrm{GPU}$ and 274.044 $\pm 0.502 \mathrm{GPU}$, respectively. When the n-hexane exchange time increased from $15 \mathrm{~min}$ (M6) to 30 min (M7), the $\mathrm{CO}_{2}$ permeance increased significantly. This is explained by the removal of 2-isopropyl alcohol from the $\mathrm{CAB}$ membrane. However, when the exchange time increased to $60 \mathrm{~min}(\mathrm{M} 5)$, the $\mathrm{CO}_{2}$ permeance reduced, due to the increase in membrane thickness that is from $4.95 \pm 0.020 \mu \mathrm{m}$ to $5.09 \pm 0.013 \mu \mathrm{m}$ (Figure 10).

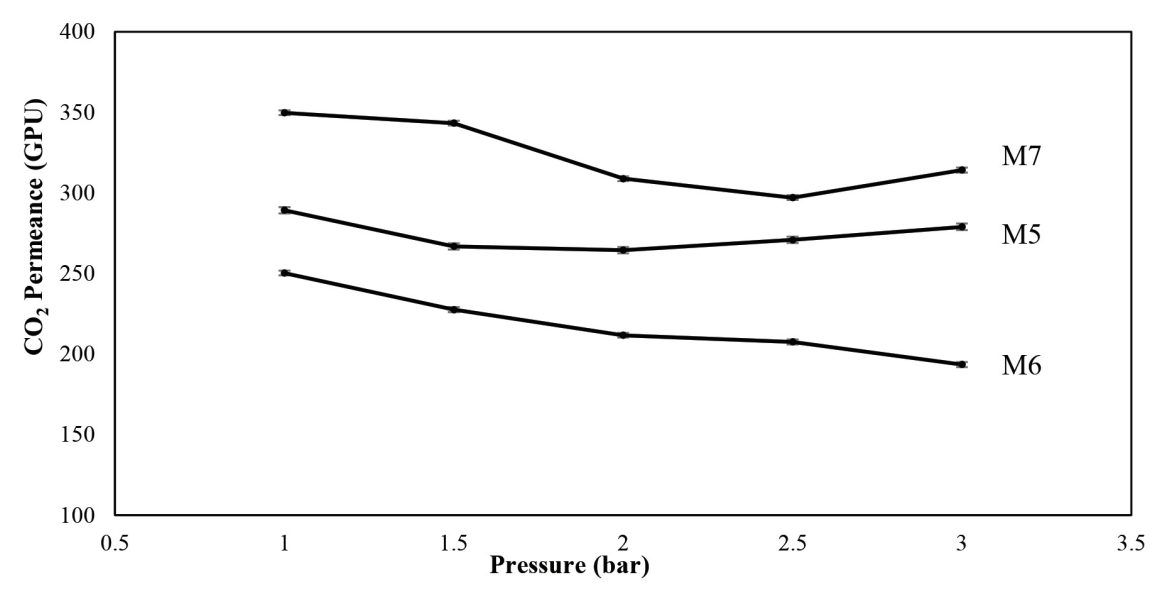

Figure 11: $\mathrm{CO}_{2}$ permeance of $\mathrm{CAB}$ membrane fabricated with $30 \mathrm{~min}$ of 2-isopropyl alcohol exchange drying time, followed by the different $n$-hexane exchange drying times with casting thickness of $250 \mu \mathrm{m}$, polymer concentration of $4 \mathrm{wt} \%$, and $5 \mathrm{~min}$ of solvent evaporation time.

As revealed in Figure 12, the $\mathrm{N}_{2}$ permeance for the membranes M6 (15 min), M7 (30 min) and M5 (60 min) are 267.032 $\pm 0.779 \mathrm{GPU}, 329.769 \pm 0.685 \mathrm{GPU}$ and $296.968 \pm 0.847 \mathrm{GPU}$, respectively. Based on these results, the optimal n-hexane exchange drying time for the synthesising of the $\mathrm{CAB}$ membrane is $30 \mathrm{~min}$. As seen from Section 3.3.2, M7 (30 min) had the thinnest membrane, i.e., $4.95 \pm$ $0.020 \mu \mathrm{m}$ when compared to M5 $(5.09 \pm 0.013 \mu \mathrm{m})$ and M6 $(8.23 \pm$ $0.041 \mu \mathrm{m})$. The reason being the thinner membrane employing a lower flow resistance to the membrane, resulting in the high separation performance of the $\mathrm{CAB}$ membrane. ${ }^{18,23}$ 


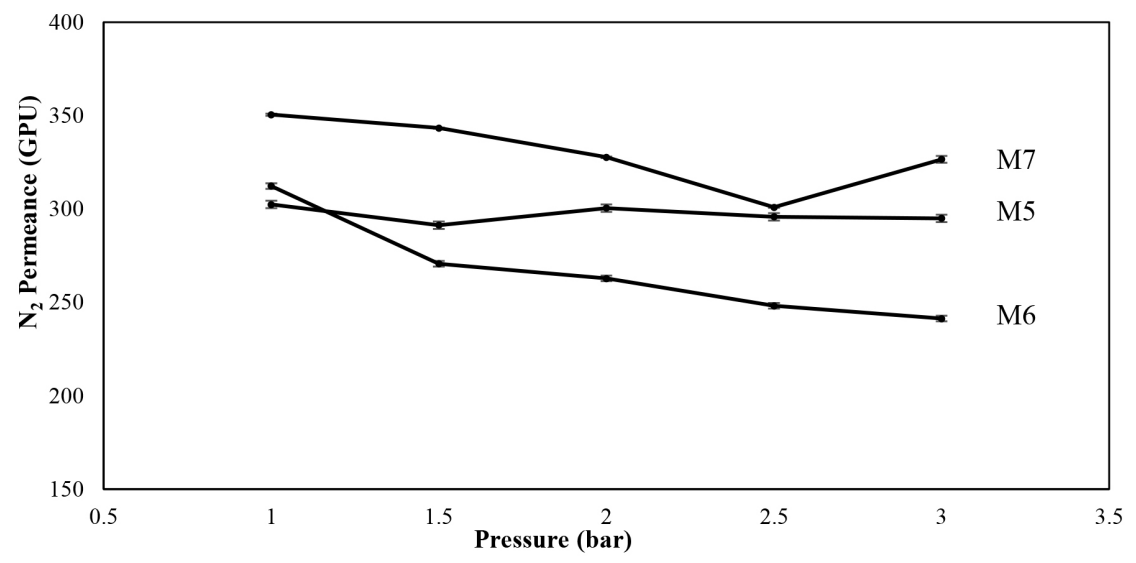

Figure 12: $\mathrm{N}_{2}$ permeance of CAB membrane fabricated with 30 min of 2-isopropyl alcohol exchange drying time, followed by the different $n$-hexane exchange drying times with casting thickness of $250 \mu \mathrm{m}$, polymer concentration of $4 \mathrm{wt} \%$, and $5 \mathrm{~min}$ of solvent evaporation time.

Figure 13 indicates the $\mathrm{CO}_{2} / \mathrm{N}_{2}$ selectivity of the synthesised $\mathrm{CAB}$ membrane with n-hexane exchange drying times of $15 \mathrm{~min}$ (M6), $30 \mathrm{~min}$ (M7) and $60 \mathrm{~min}$ (M5). The membranes M6, M7 and M5 have a selectivity of $0.817 \pm 0.009,0.978$ \pm 0.011 and $0.923 \pm 0.013$, respectively. As shown in Figure 13, the separation performance of M6 (15 min) is poor when compared to M7 (30 min) and M5 (60 $\mathrm{min})$. This was mainly due to the insufficient exchange drying time of n-hexane to replace all the 2-isopropyl alcohol molecules within the membrane structure, thus forming a thick membrane (M6) with thickness of $8.23 \pm 0.041 \mu \mathrm{m}$. On the other hand, when the n-hexane exchange time increased from $15 \mathrm{~min}$ to $30 \mathrm{~min}$, the $\mathrm{CO}_{2} / \mathrm{N}_{2}$ selectivity of the $\mathrm{CAB}$ membrane increased significantly. This was because of the sufficient exchange time that produced a thin membrane (M7) with a thickness of $4.96 \pm 0.020 \mu \mathrm{m}$. Conversely, a longer n-hexane exchange time deformed the original membrane structure with the excessive n-hexane exchange time and resulted in a thick membrane (M5) with a thickness of $5.09 \pm 0.013 \mu \mathrm{m}$. Thus, the selectivity of the membrane was affected. ${ }^{12}$ 


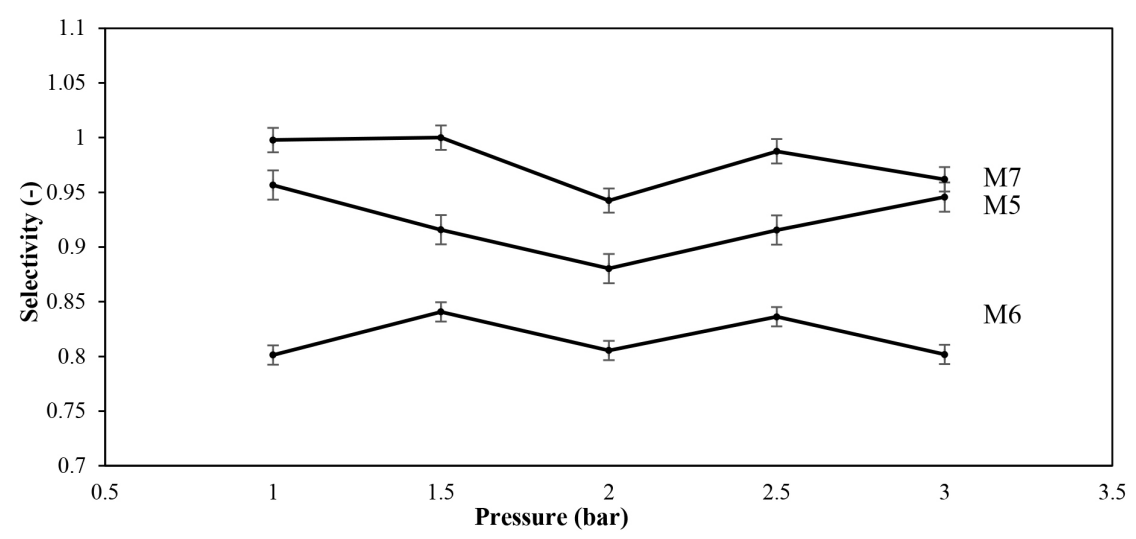

Figure 13: Selectivity of CAB membrane fabricated with $30 \mathrm{~min}$ of 2-isopropyl alcohol exchange drying time, followed by the different $n$-hexane exchange drying times with casting thickness of $250 \mu \mathrm{m}$, polymer concentration of $4 \mathrm{wt} \%$, and $5 \mathrm{~min}$ of solvent evaporation time.

As shown in Figure 14, the ATR-FTIR spectra of M2 (optimum solvent evaporation time membrane) and M7 (optimum solvent exchange drying time membrane) illustrates the characteristic peaks, which differentiates the chemical structure of the membranes. ${ }^{27}$ All bondings were described in Section 3.1.2. The results of the ATR-FTIR spectra were used to indicate the presence of CAB groups and their interactions in the polymer matrix, which aids in the $\mathrm{CO}_{2} / \mathrm{N}_{2}$ gas separation. According to Zhang et al., $\mathrm{CO}_{2}$ is considered as one of the gas-responsive polymers where it can interact with the $\mathrm{CAB}$ polymer chains and functional groups as mentioned above. ${ }^{25}$ Thus, the $\mathrm{CO}_{2}$ gas permeates through the $\mathrm{CAB}$ membrane much more effectively.

Moreover, the $\mathrm{CO}_{2}$ permeance of the $\mathrm{CAB}$ membrane prepared with 2-isopropyl alcohol and $\mathrm{n}$-hexane exchange drying time of $30 \mathrm{~min}$ (M7) is higher (322.603 \pm $0.467 \mathrm{GPU}$ ) when compared to preparing with the optimum solvent evaporation time of $5 \mathrm{~min}(\mathrm{M} 2,205.093 \pm 1.225 \mathrm{GPU})$. This can be explained by referring to Figure 14, where the transmittance peaks of M7 are shown to be slightly higher as compared to M2. Thus, a higher $\mathrm{CO}_{2} / \mathrm{N}_{2}$ selectivity can be obtained by $\mathrm{M} 7$. 


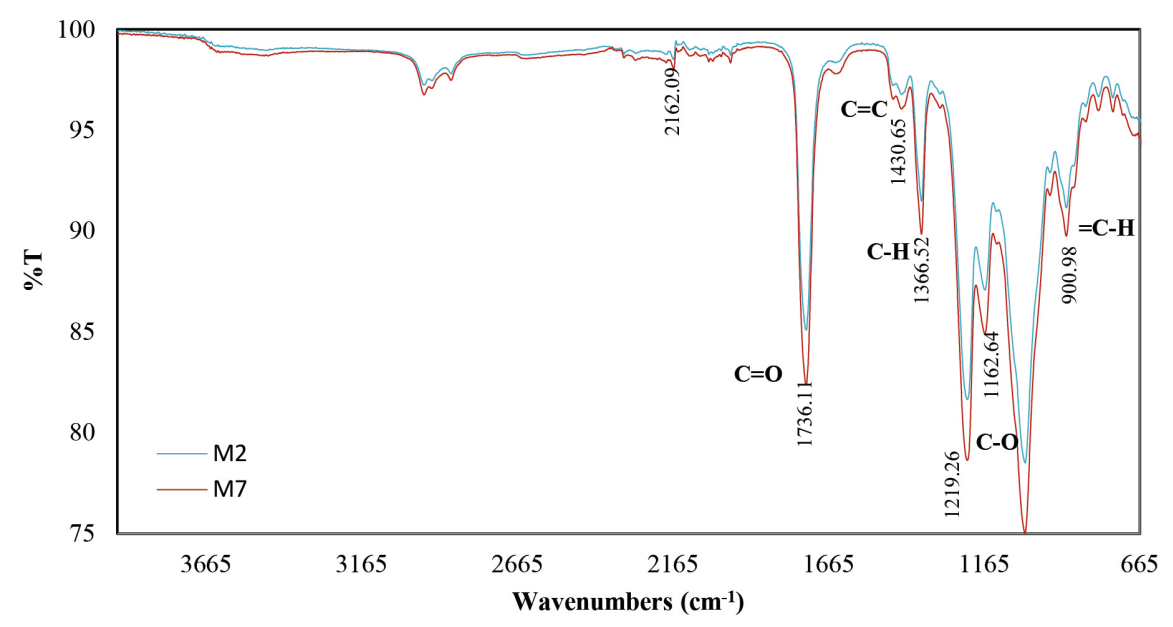

Figure 14: ATR-FTIR spectra of the optimum CAB membrane from the effect of solvent evaporation (M2) and solvent exchange drying time (M7), with casting thickness of $250 \mu \mathrm{m}$ and $4 \mathrm{wt} \%$ of CAB polymer concentration.

\subsection{MMM}

In order to optimise the $\mathrm{CAB}$ membrane performance, $\mathrm{MMM}$ is synthesised by using $4 \mathrm{wt} \%$ of CAB polymer matrix and $0.1 \mathrm{wt} \%$ of MWCNTs-F, with casting thickness of $250 \mu \mathrm{m}$, solvent evaporation time of $5 \mathrm{~min}$, solvent exchange drying time of 30 min of 2-isopropyl alcohol followed by $30 \mathrm{~min}$ of $\mathrm{n}$-hexane. Next, the effects of different MWCNTs loadings and acetyl contents on gas separation performances were investigated. The MMMs prepared using different MWCNT loadings and acetyl contents were discussed based on the membrane surface morphology and then evaluated by using the single gas permeation test for $\mathrm{CO}_{2} /$ $\mathrm{N}_{2}$ separation.

\subsubsection{Membrane characterisation}

The synthesised MMM's surface morphology was determined by using the SEM as presented in Figure 15. As observed from Figure 15(a), the MMM surface has some clusters of MWCNTs-F, which proves the formation of MMM. As for the cross-sectional area in Figure 15, it is observed that the membrane thickness of MMM- $0.1 \mathrm{~F}$ is $6.413 \pm 0.025 \mu \mathrm{m}$. 

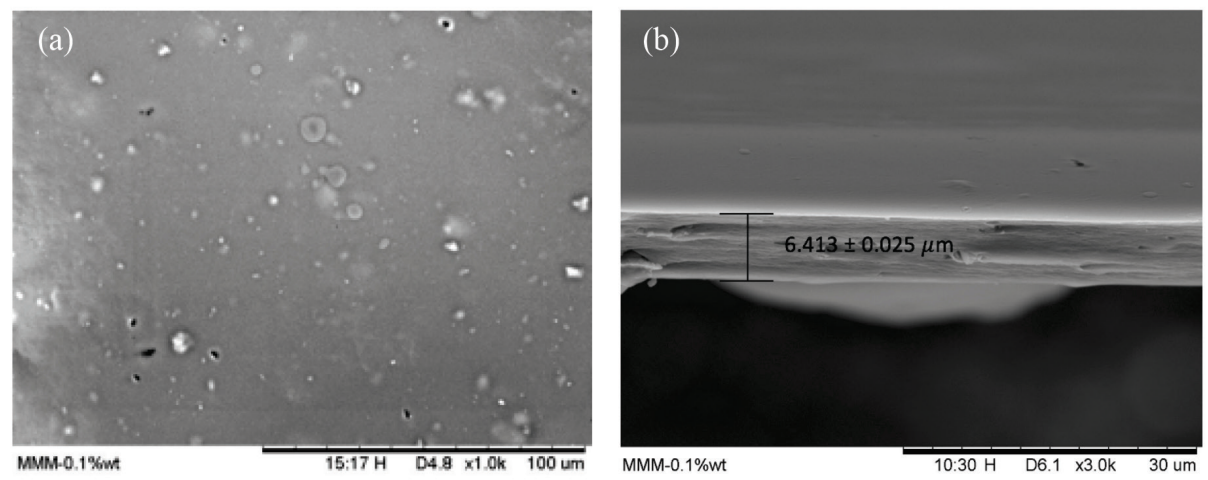

Figure 15: SEM micrographs of (a) membrane surface, and (b) cross-sectional structure of MMM0.1-F, synthesised with $4 \mathrm{wt} \%$ of CAB polymer concentration and $0.1 \mathrm{wt} \%$ of MWCNTs, with casting thickness of $250 \mu \mathrm{m}, 5 \mathrm{~min}$ solvent evaporation time, solvent exchange drying time of 30 min each for 2-isopropyl alcohol and n-hexane.

\subsubsection{Separation performance of the membranes}

The $\mathrm{CO}_{2}$ permeance of the MMM0.1-F and the neat membrane (M7) are compared in Figure 16. The $\mathrm{CO}_{2}$ permeance of the MMM0.1-F is 351.152 $\pm 2.464 \mathrm{GPU}$, which is higher than the optimised $\mathrm{CAB}$ membrane from both the solvent evaporation time and solvent exchange drying time (M7). Conversely, the $\mathrm{N}_{2}$ permeance obtained for MMM0.1-F obtained is $119.819 \pm 0.573 \mathrm{GPU}$, which is much lower than the $\mathrm{N}_{2}$ permeance of M7 (329.769 $\left.\pm 0.685 \mathrm{GPU}\right)$, as presented in Figure 17. As shown in Figure 18, this results in high membrane selectivity of MMM0.1-F, which is $2.935 \pm 0.062$. The considerable improvement in the membrane performance was due to the addition of the inorganic fillers (MWCNTs-F), which created favourable permeation pathways for selective permeance, while giving a barrier for the unfavourable permeation to improve the separation performance, thus, increasing the membrane selectivity. ${ }^{28}$ The introduction of the MWCNTs-F increased the free volume space and improved the gas permeance by reducing the molecular chain packing. ${ }^{29}$ As a result the membrane performance of the MMM-0.1F significantly increased. 


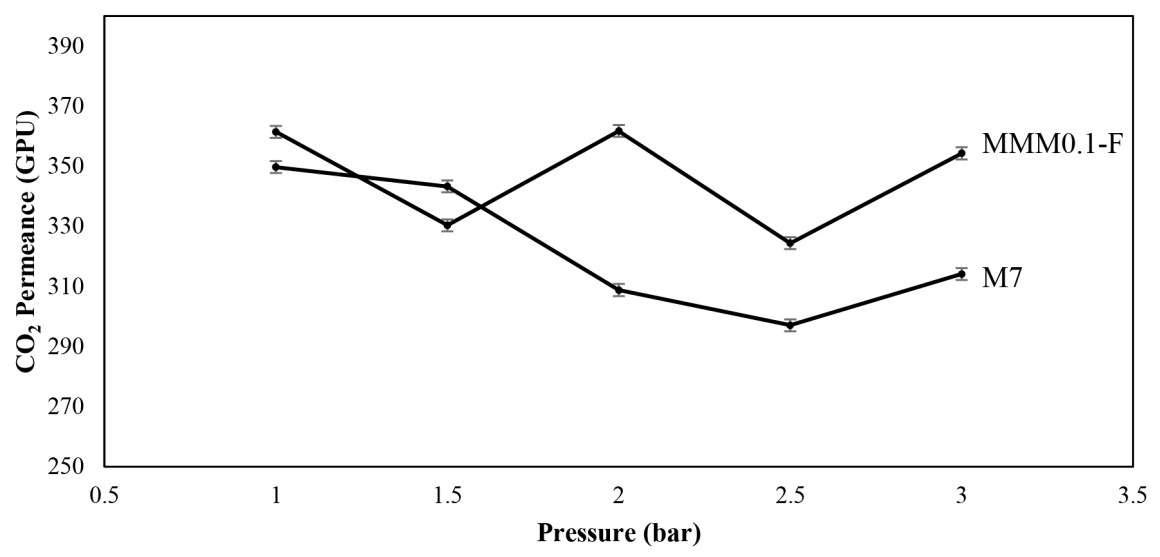

Figure 16: $\mathrm{CO}_{2}$ permeance for MMM-0.1F fabricated with $4 \mathrm{wt} \%$ of $\mathrm{CAB}$ polymer concentration and $0.1 \mathrm{wt} \%$ of MWCNTs, and M7 fabricated with $4 \mathrm{wt} \%$ of $\mathrm{CAB}$ polymer concentration, with casting thickness of $250 \mu \mathrm{m}, 5 \mathrm{~min}$ solvent evaporation time, solvent exchange drying time of 30 min each for 2-isopropyl alcohol and n-hexane.

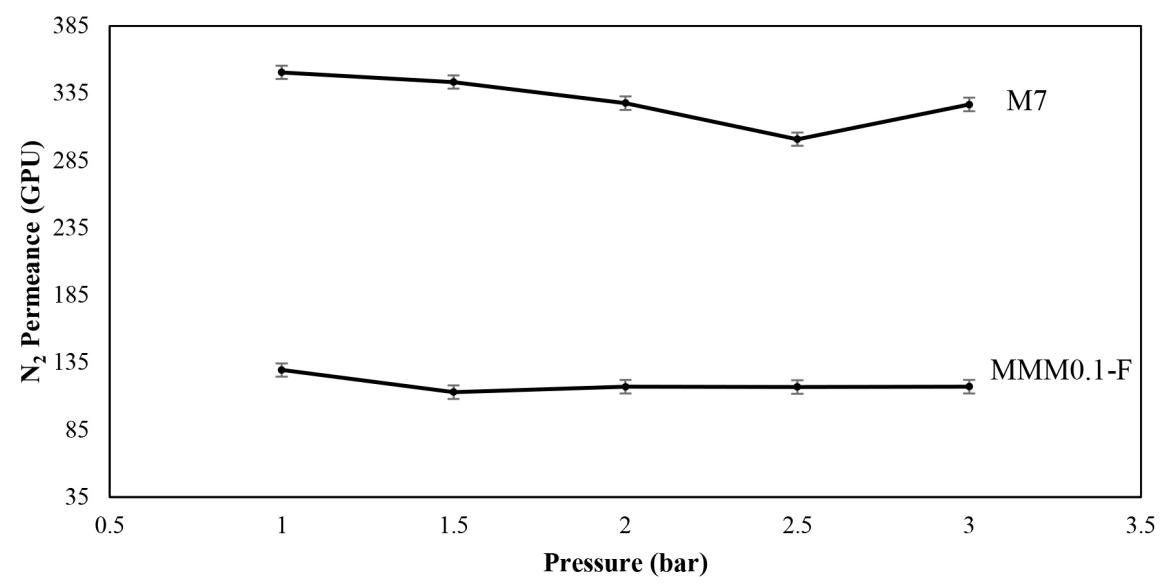

Figure 17: $\mathrm{N}_{2}$ permeance for MMM-0.1F fabricated with $4 \mathrm{wt} \%$ of CAB polymer concentration and $0.1 \mathrm{wt} \%$ of MWCNTs, and M7 fabricated with $4 \mathrm{wt} \%$ of $\mathrm{CAB}$ polymer concentration, with casting thickness of $250 \mu \mathrm{m}, 5 \mathrm{~min}$ solvent evaporation time, solvent exchange drying time of $30 \mathrm{~min}$ each for 2-isopropyl alcohol and n-hexane.

Figure 19 indicates that the $\mathrm{CO}_{2} / \mathrm{N}_{2}$ selectivity of the MMM-0.1F is $2.935 \pm 0.062$, thereby exhibiting a major improvement as compared to $\mathrm{M} 7(0.978 \pm 0.011)$. 
This was due to the appropriate free volumes involving the polymer chains and the polymer/MWCNTs-F interface, resulting in the interaction of $\mathrm{CAB}$ polymer and MWCNTs. ${ }^{30}$ Besides that, there was the bonding of the hydroxyl functional group on the beta-cyclodextrin (-CD) when compared to pristine MWCNTs. ${ }^{31}$ This caused the better selectivity for MMM.

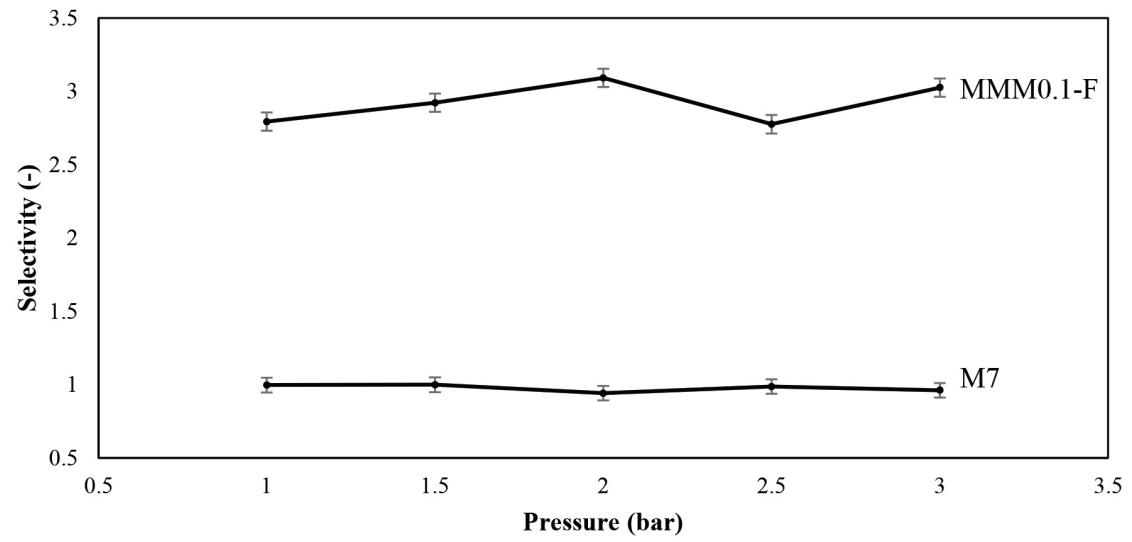

Figure 18: Selectivity for MMM-0.1F fabricated with $4 \mathrm{wt} \%$ of CAB polymer concentration and $0.1 \mathrm{wt} \%$ of MWCNTs, and M7 fabricated with $4 \mathrm{wt} \%$ of $\mathrm{CAB}$ polymer concentration, with casting thickness of $250 \mu \mathrm{m}, 5 \mathrm{~min}$ solvent evaporation time, solvent exchange drying time of 30 min each for 2-isopropyl alcohol and n-hexane.

\subsection{Effect of Different MWCNTs Loadings}

\subsubsection{Membrane characterisation}

Figures 19(a, c, e, g and i) illustrate the surface of the MMM prepared with molecular weight $(\mathrm{Mn})$ of 70000 and different MWCNTs loadings of 0.2 wt\% (MMM-0.2F), 0.7 wt\% (MMM-0.7F), $1.0 \mathrm{wt} \%$ (MMM-1.0F), $1.2 \mathrm{wt} \%$ (MMM-1.2F) and $2.5 \mathrm{wt} \%$ (MMM-2.5F). As seen from the SEM images, these membranes have a rough surface because of the defects and interface voids found on the surface. Clusters of nanotubes were also observed on the membrane surface. The formation of clusters was due to agglomeration. This was because the interaction between the nanotubes was stronger than that with the polymer matrix. The amount of both the interface voids and agglomeration was dependent on the MWCNTs loadings. As the loadings increased, more interface voids and agglomeration were found on the membrane surface.$^{32}$ Figures 19(b, d, f, h and j) demonstrates the membrane thickness of MMM-0.2F, 
MMM-0.7F, MMM-1.0F, MMM-1.2F and MMM-2.5F. The thickness of these five membranes were measured to be approximately $8.765 \pm 0.1049 \mu \mathrm{m}, 5.793 \pm 0.097$ $\mu \mathrm{m}, 17.099 \pm 0.101 \mu \mathrm{m}, 13.881 \pm 0.145 \mu \mathrm{m}$ and $64.264 \pm 0.471 \mu \mathrm{m}$, respectively. The changes in the membrane thickness were due to the amount of suspensions used to prepare the MMM. ${ }^{33}$ The amount of the MWCNT loading had also a significant effect on the membrane thickness. Based on Figure 19, the thickness of the membrane decreased when the loading increased up to $0.7 \mathrm{wt} \%$ (MMM$0.7 \mathrm{~F})$ due to the increase in the viscosity of the solution. However, the membrane thickness increased when the loading was further increased to $1.2 \mathrm{wt} \%$ (MMM1.2F). This was because the MWCNTs increased the miscibility gap induced by the MWCNTs that work as non-solvent for the polymer (thermodynamic effect on the phase separation, i.e., less water is required to induce phase separation). ${ }^{34}$ Besides, a significant change in the structure of the membrane was also observed. The SEM image displayed a dense structure in the MMM-0.2F. As the MWCNTs loading increased, a porous structure was found in the MMM-2.5F. This was because the porosity of the membrane increased when the MWCNTs loading increased up to $2.5 \mathrm{wt} \%$. The increased porosity caused the mechanical strength of the membrane to decrease. ${ }^{35}$ When compared to other membranes, the MMM-2.5F had poor mechanical strength and low ability to build up the pressure. Therefore, it was excluded from the performance test of this study. 

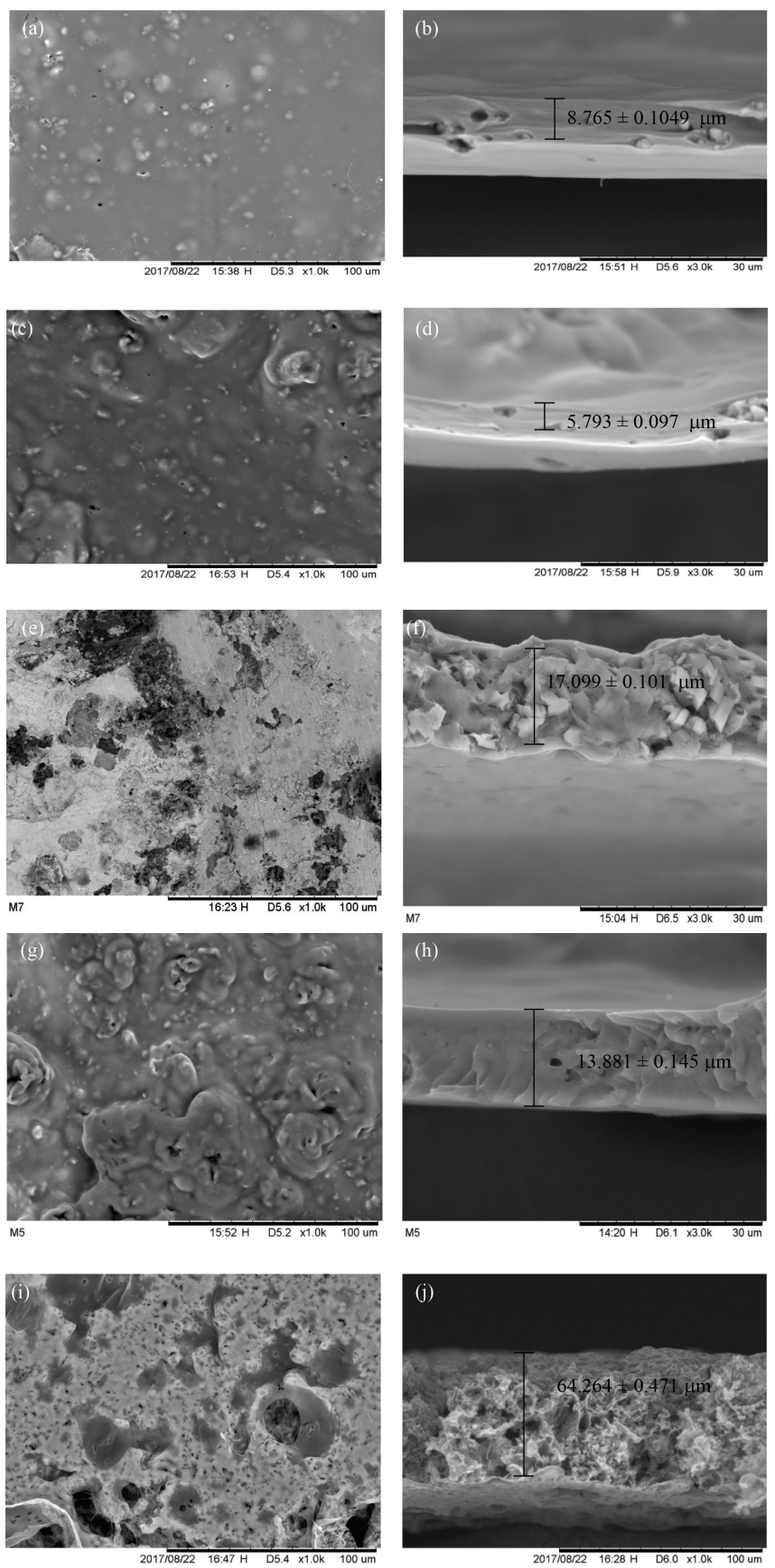

Figure 19: SEM surface and cross-section of MMMs prepared with Mn of 70000 and casting thickness of $250 \mu \mathrm{m}$ with different MWCNT loadings of (a, b) $0.2 \mathrm{wt} \%$, (c, d) $0.7 \mathrm{wt} \%$, (e, f) $1.0 \mathrm{wt} \%$, (g, h) $1.2 \mathrm{wt} \%$, and (i, j) $2.5 \mathrm{wt} \%$. 


\subsubsection{Separation performance of the membranes}

The performance of the MMM prepared with molecular weight (Mn) of 70000 and different MWCNT loadings of $0.2 \mathrm{wt} \%$ (MMM-0.2F), $0.7 \mathrm{wt} \%$ (MMM-0.7F), 1.0 wt $\%$ (MMM-1.0F) and $1.2 \mathrm{wt} \%$ (MMM-1.2F) was evaluated by using the $\mathrm{CO}_{2}$ and $\mathrm{N}_{2}$ single gas permeation test. The effect of the different MWCNTs loadings on $\mathrm{CO}_{2}$ is observed in Figure 20. It can be seen that the $\mathrm{CO}_{2}$ permeance increased when the loading increased up to $0.7 \mathrm{wt} \%$ (MMM-0.7F) and then decreased when the loading was further increased to $1.2 \mathrm{wt} \%$ (MMM-1.2F). The MMM-0.7F obtained the highest $\mathrm{CO}_{2}$ permeance. Based on this, it can be concluded that more free volume cavities were introduced between the polymer matrix and nanotubes when compared to the other synthesised membranes as discussed by Ahmad et al. ${ }^{18}$ Hence, more polymer chain packings were disturbed and the gas diffusions were enhanced. However, the reduction of $\mathrm{CO}_{2}$ permeance in both the MMM-1.0F and the MMM-1.2F was due to the formation of more clusters in the polymer matrix. ${ }^{33}$

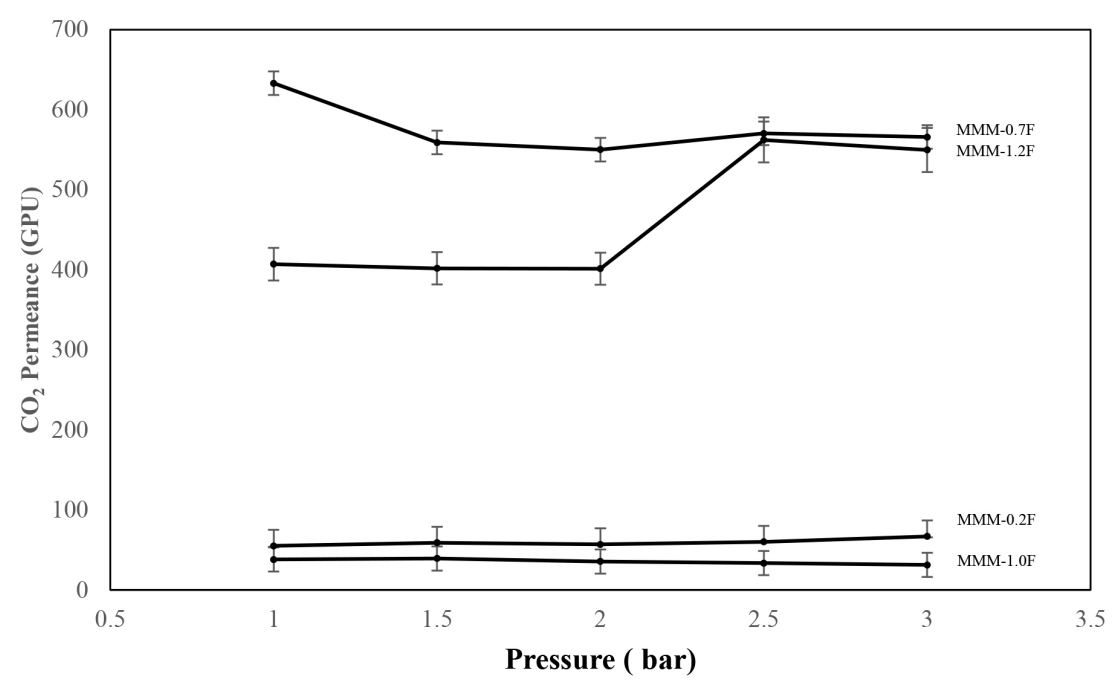

Figure 20: $\mathrm{CO}_{2}$ permeance of MMMs prepared with $\mathrm{Mn}$ of 70000 and casting thickness of $250 \mu \mathrm{m}$ with different MWCNT loadings of $0.2 \mathrm{wt} \%, 0.7 \mathrm{wt} \%, 1.0 \mathrm{wt} \%$ and $1.2 \mathrm{wt} \%$.

Figure 21 explains the effect of different MWCNT loadings on $\mathrm{N}_{2}$ permeance. It is observed that $\mathrm{N}_{2}$ permeance increases when the loadings increased up to $0.7 \mathrm{wt} \%$ (MMM-0.7F) and then reduces when the loading is further increased to $1.0 \mathrm{wt} \%$ (MMM-1.0F). With low MWCNT loadings of $0.2 \mathrm{wt} \%$ and $0.7 \mathrm{wt} \%$, the free volume cavities increased thereby causing an increment of the $\mathrm{N}_{2}$ permeance. ${ }^{33}$ 
Meanwhile, the loading of $1.0 \mathrm{wt} \%$ caused the reduction in the permeance of $\mathrm{N}_{2}$ gas due to the control amount of MWCNTs-F, which dispersed homogenously within the polymeric membrane structure as schematically described by Ahmad et al. ${ }^{18}$ However, at a higher MWCNTs concentration of $1.2 \mathrm{wt} \%$, the MWCNTs tended to agglomerate and caused the permeance of $\mathrm{N}_{2}$ to decrease due to van der Waals forces. ${ }^{32}$

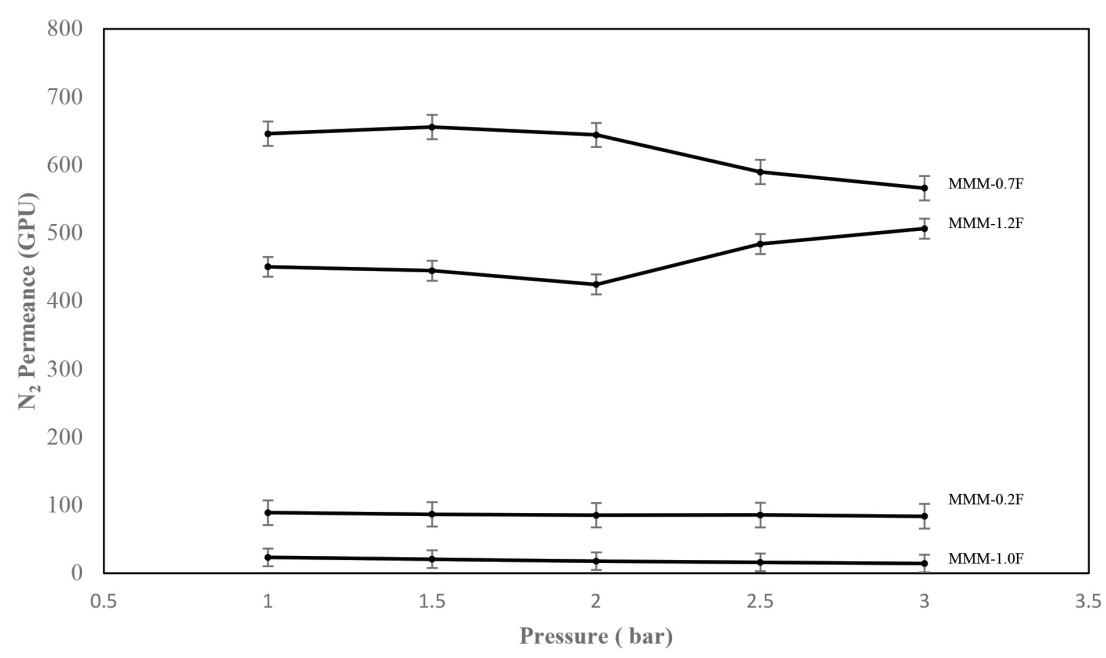

Figure 21: $\mathrm{N}_{2}$ permeance of MMMs prepared with Mn of 70000 and casting thickness of $250 \mu \mathrm{m}$ with different MWCNT loadings of $0.2 \mathrm{wt} \%, 0.7 \mathrm{wt} \%, 1.0 \mathrm{wt} \%$ and $1.2 \mathrm{wt} \%$.

Figure 22 presents the effect of different MWCNT loadings on $\mathrm{CO}_{2} / \mathrm{N}_{2}$ selectivity. Based on this figure, the highest $\mathrm{CO}_{2} / \mathrm{N}_{2}$ selectivity of 1.9740 was achieved for the MMM with MWCNTs content of $1.0 \mathrm{wt} \%$. Meanwhile, the lowest $\mathrm{CO}_{2} / \mathrm{N}_{2}$ selectivity of 0.6948 was when the MMM was prepared with MWCNT loading of $0.2 \mathrm{wt} \%$ (MMM-0.2F). In this study, the $\mathrm{CO}_{2} / \mathrm{N}_{2}$ selectivity increased when the loading increased from $0.2 \mathrm{wt} \%$ to $1.0 \mathrm{wt} \%$ (MMM-1.0F) due to the $\mathrm{CO}_{2}$ diffusivity within the MMM structure. However, a further increase of MWCNT loading up to $1.2 \mathrm{wt} \%(\mathrm{MMM}-1.2 \mathrm{~F})$ resulted in decrease of the $\mathrm{CO}_{2} / \mathrm{N}_{2}$ selectivity. This reduction was due to the agglomeration of the MWCNTs where, the agglomerated nanotubes reduced the accessible diffusive pathway for the diffusion. ${ }^{32}$ 


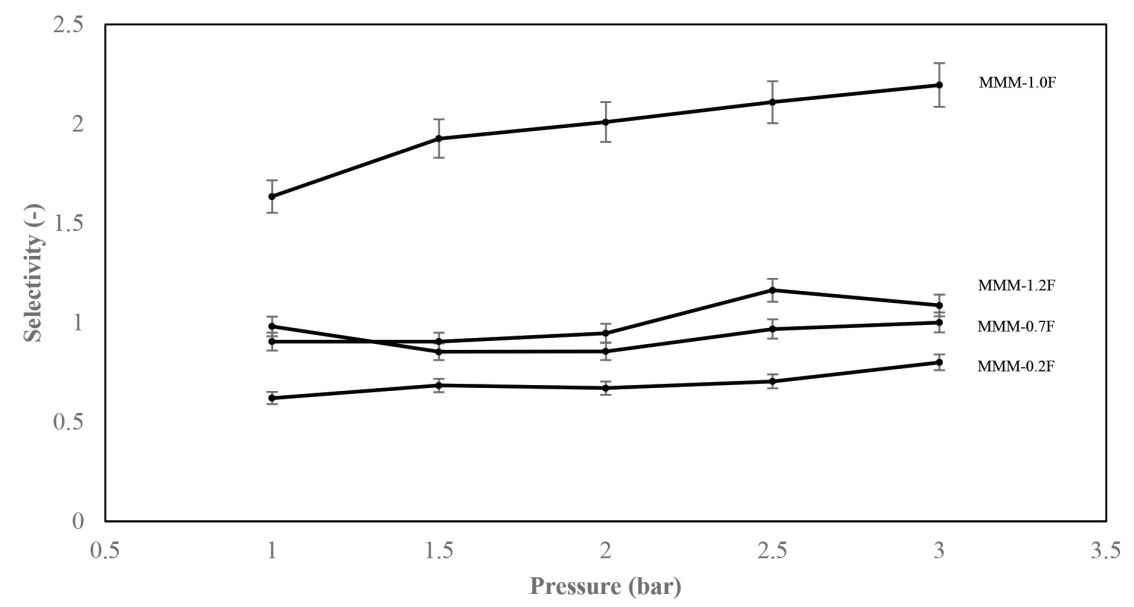

Figure 22: $\mathrm{CO}_{2} / \mathrm{N}_{2}$ selectivity of MMM prepared with $\mathrm{Mn}$ of 70000 and casting thickness of $250 \mu \mathrm{m}$ with different MWCNTs loadings of $0.2 \mathrm{wt} \%, 0.7 \mathrm{wt} \%, 1.0 \mathrm{wt} \%$ and $1.2 \mathrm{wt} \%$.

\subsection{Effect of Different Acetyl Contents}

\subsubsection{Membrane characterisation}

The surface of the MMMs prepared with $\mathrm{CAB}$ polymer of different Mn 70000 (MMM-70000) with acetyl content from $12 \mathrm{wt} \%$ to $15 \mathrm{wt} \%$ and Mn 65000 (MMM65000 ) with acetyl content from $28 \mathrm{wt} \%$ to $31 \mathrm{wt} \%$ with MWCNTs loading of $0.7 \mathrm{wt} \%$ are shown in Figure 23(a and c). As seen from this figure, the membranes have a rough surface. The defects and interface voids were found on the surface of both membranes. The nanotubes also tended to agglomerate because the interaction between the nanotubes was stronger than that with the polymer matrix. Therefore, the nanotubes were not well dispersed throughout the polymer matrix. ${ }^{32}$

Figure 23(b and d) illustrates the thickness of the MMM prepared with CAB polymer of different Mn 70000 (MMM-70000) and Mn 65000 (MMM-65000) with MWCNTs loading of $0.7 \mathrm{wt} \%$. The thickness of these two membranes was measured to be approximately $5.793 \pm 0.097 \mu \mathrm{m}$, and $13.465 \pm 0.088 \mu \mathrm{m}$ respectively. Due to the uncontrolled loading inside the MMM-65000, a thicker membrane was obtained as compared to MMM-70000 where, the loading of the MMM-70000 was studied and discussed in Section 3.5. 

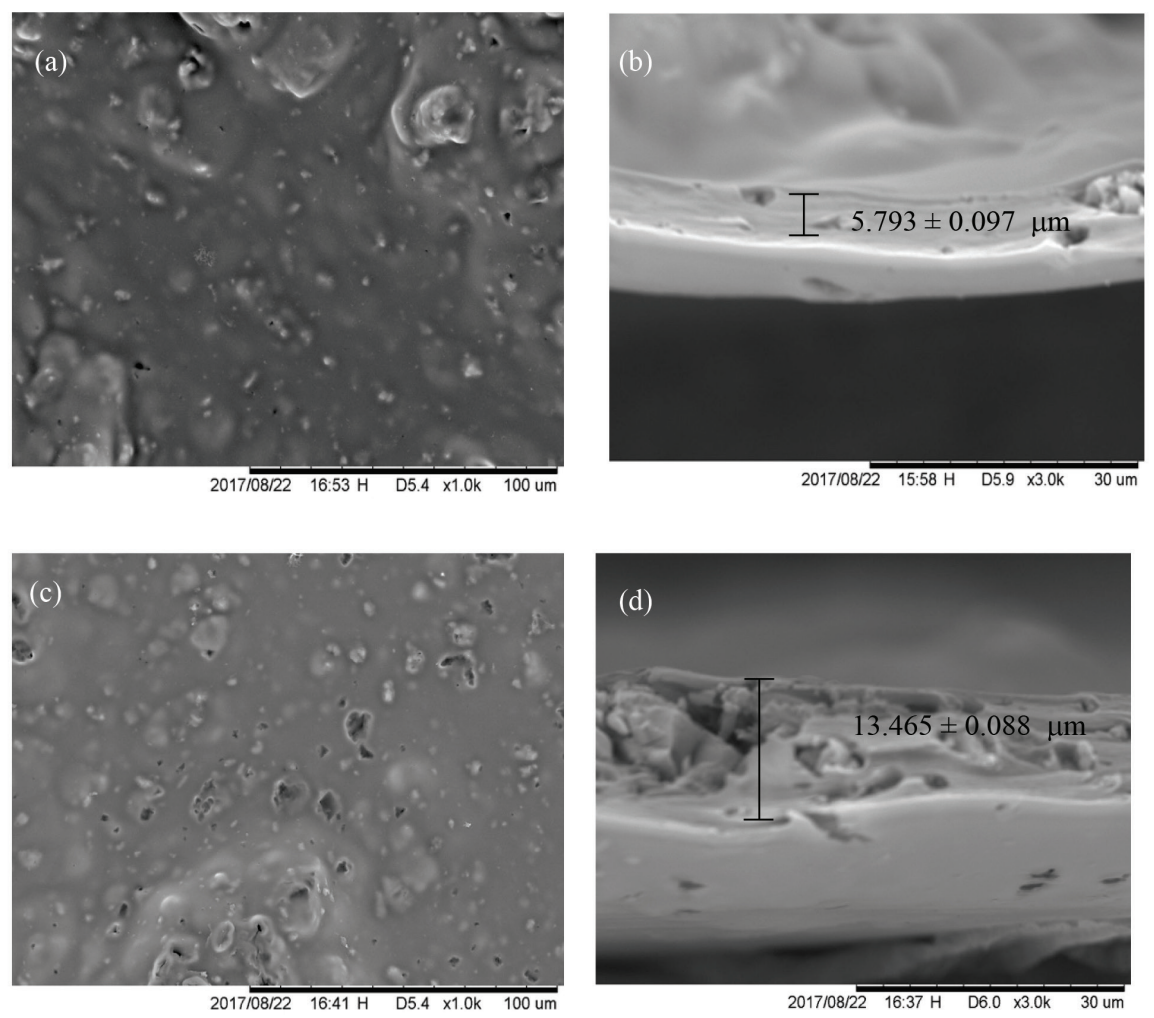

Figure 23: SEM surface and cross-section of MMMs prepared with casting thickness of $250 \mu \mathrm{m}$ and MWCNTs loading of $0.7 \mathrm{wt} \%$ at different Mn of $(\mathrm{a}, \mathrm{b}) 70000$ and (c, d) 65000 .

\subsubsection{Separation performance of the membranes}

The performance of the MMMs prepared with CAB polymer of Mn 70000 (MMM70000) with acetyl content from $12 \mathrm{wt} \%$ to $15 \mathrm{wt} \%$ and Mn 65000 (MMM-65000) with acetyl content from $28 \mathrm{wt} \%$ to $31 \mathrm{wt} \%$ with MWCNT loading of $0.7 \mathrm{wt} \%$ was evaluated by using the $\mathrm{CO}_{2}$ and $\mathrm{N}_{2}$ single gas permeation test. The effect of the acetyl contents on the $\mathrm{CO}_{2}$ permeance is shown in Figure 24. In this figure, the highest $\mathrm{CO}_{2}$ permeance obtained was $718.9538 \pm 17.2773 \mathrm{GPU}$ for the MMM65000. The increased in the $\mathrm{CO}_{2}$ permeance for MMM-65000 can be explained by the presence of the acetyl content, which increased from 70000 to 65000 . With higher acetyl content (from $28 \mathrm{wt} \%$ to $31 \mathrm{wt} \%$ ), more hydrogen bonding was reduced and hence, increasing the mobility of the chains. As a result, the $\mathrm{CO}_{2}$ permeance increased to $718.9538 \pm 17.2773 \mathrm{GPU}$ as more $\mathrm{CO}_{2}$ molecules were absorbed and diffused through the denser layer of the membrane. ${ }^{36}$ 


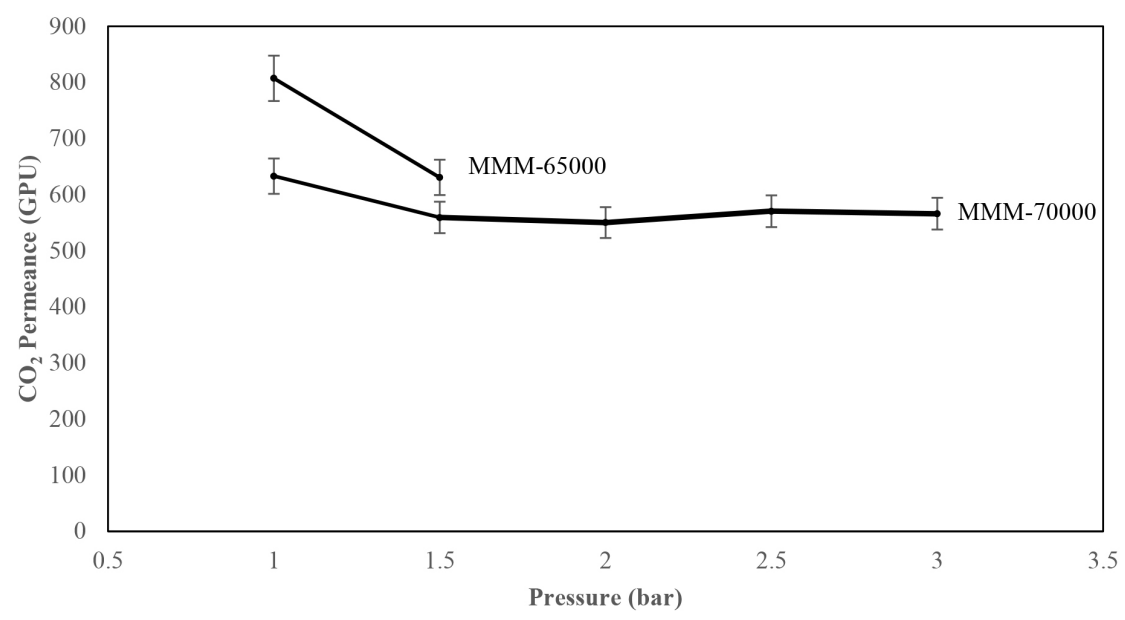

Figure 24: $\mathrm{CO}_{2}$ permeance of MMMs prepared with casting thickness of $250 \mu \mathrm{m}$ and MWCNTs loading of $0.7 \mathrm{wt} \%$ at different Mn of 70000 and 65000.

This can be confirmed based on the ATR-FTIR analysis, which is presented in Figure 25. As regards to the MMM-65000, the $\mathrm{C}=\mathrm{O}$ and $\mathrm{C}-\mathrm{O}-\mathrm{C}$ bond sketching were observed at $1735.91 \mathrm{~cm}^{-1}$ and $1219.28 \mathrm{~cm}^{-1}$, respectively. The $\mathrm{O}-\mathrm{H}$ bending was also observed at $1430.88 \mathrm{~cm}^{-1}$ for MMM-65000. On the other hand, the $\mathrm{C}=\mathrm{O}$ and $\mathrm{C}-\mathrm{O}-\mathrm{C}$ bond sketching for the MMM-70000 were observed at $1736.06 \mathrm{~cm}^{-1}$ and $1225.88 \mathrm{~cm}^{-1}$, respectively. The $\mathrm{O}-\mathrm{H}$ bending was observed at $1457.97 \mathrm{~cm}^{-1} .^{37}$ When compared to the MMM-70000, the MMM-65000 had a lower value of O-H bands, $\mathrm{C}=\mathrm{O}$ bands and also $\mathrm{C}-\mathrm{O}-\mathrm{C}$ bands. The lower value of the bands indicated the increase in chains mobility and, which then increased the $\mathrm{CO}_{2}$ permeance. ${ }^{38}$ However, the mechanical strength of the MMM-65000 was poor as the pressure could only stand until 1.5 bar due to the highly agglomerated MWCNTs. Besides, the MMM with Mn of 12000 (MMM-12000) and MWCNTs loading of $0.7 \mathrm{wt} \%$ was also prepared for this research study. However, the MMM-12000 was very difficult to form due to the low viscosity of the casting solution. 


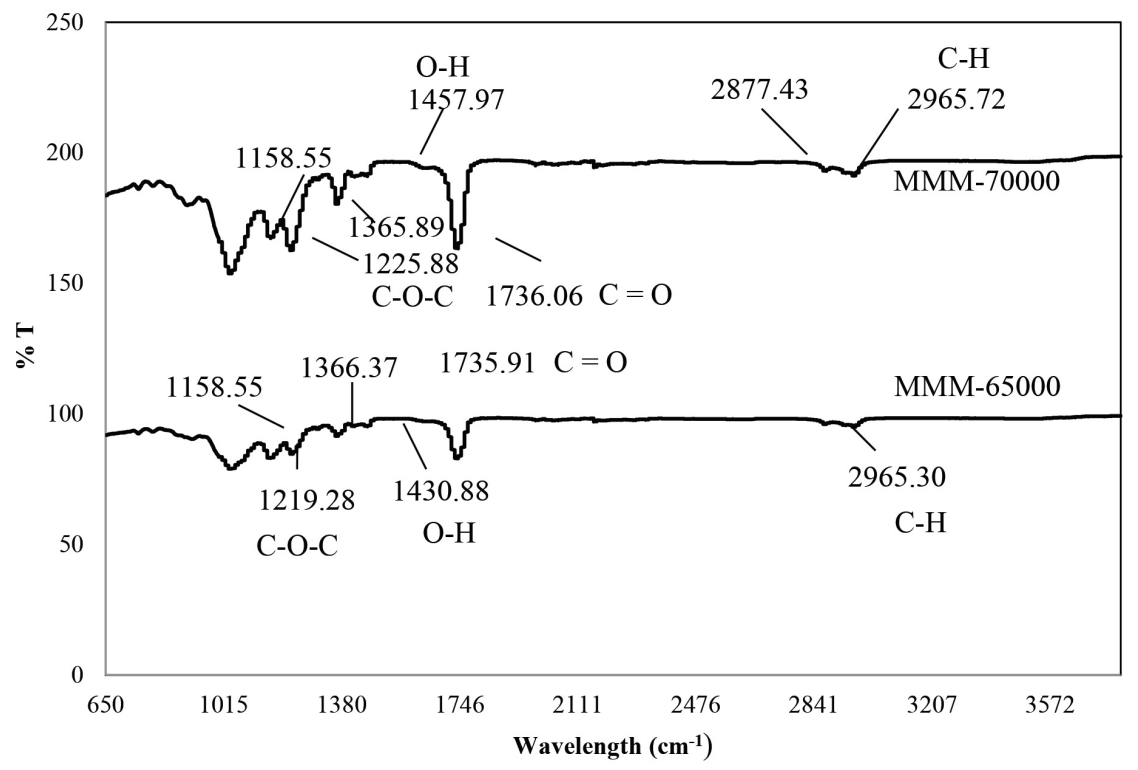

Figure 25: ATR-FTIR of MMM prepared with CAB polymer with Mn of 65000 and 70000 and MWCNT loading of $0.7 \mathrm{wt} \%$ with casting thickness of $250 \mu \mathrm{m}$.

The $\mathrm{N}_{2}$ permeance for MMM-65000 and MMM-70000 is compared in Figure 26. Based on this figure, the $\mathrm{N}_{2}$ permeance increase in the acetyl contents from 12-15 wt\% (MMM-70000) to 28-31 wt\% (MMM-65000). This was due to the increase in interaction between the polar molecules (acetyl group) and nonpolar molecules $\left(\mathrm{N}_{2}\right)$. Therefore, the $\mathrm{N}_{2}$ permeance for MMM-65000 was higher for MMM-70000. The highest $\mathrm{N}_{2}$ permeance obtained was $785.5473 \pm 11.7800$ GPU for the MMM-65000 with a pressure of 1.5 bars only.

Figure 27 describes the $\mathrm{CO}_{2} / \mathrm{N}_{2}$ selectivity for MMMs with different acetyl contents in the $\mathrm{CAB}$ polymer. As seen in this figure, the acetyl content in the $\mathrm{CAB}$ polymer did not affect the $\mathrm{CO}_{2} / \mathrm{N}_{2}$ selectivity significantly. The $\mathrm{CO}_{2} / \mathrm{N}_{2}$ selectivity obtained for both the membranes were close which was in the range of 0.9227 to 0.9308 . Therefore, it can be concluded that the gas permeance of the membranes would be increased at the higher acetyl content (from $28 \mathrm{wt} \%$ to $31 \mathrm{wt} \%$ ) without scarifying the $\mathrm{CO}_{2} / \mathrm{N}_{2}$ selectivity. This might be due to the uncontrolled loading of MWCNTs inside the MMM-65000. However, this was not investigated intensively in this study. 


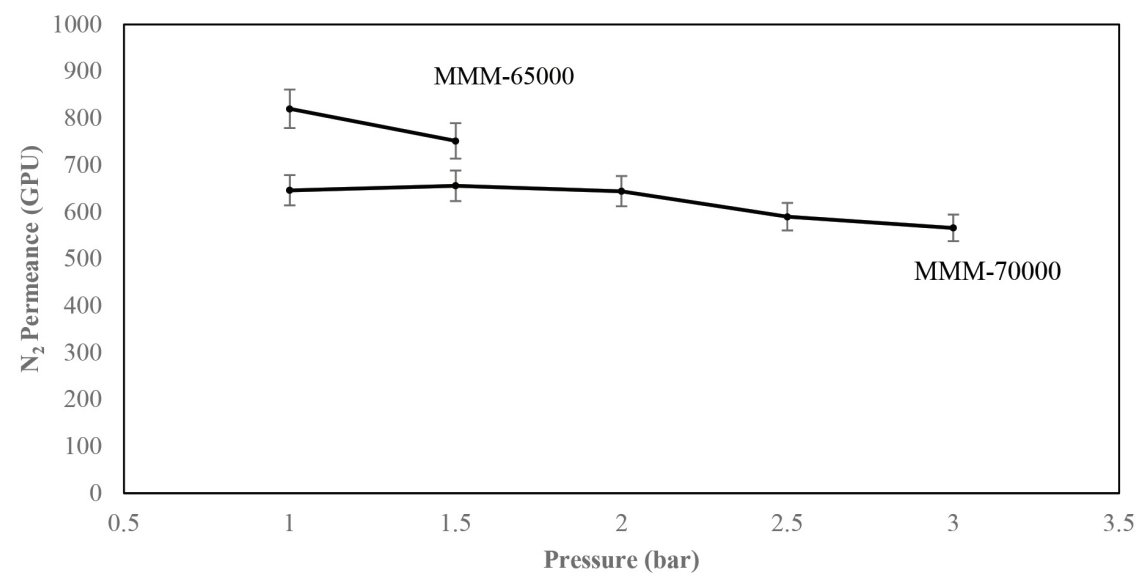

Figure 26: $\mathrm{N}_{2}$ permeance of MMMs prepared with casting thickness of $250 \mu \mathrm{m}$ and MWCNT loading of $0.7 \mathrm{wt} \%$ and with different Mn of 70000 and 65000.

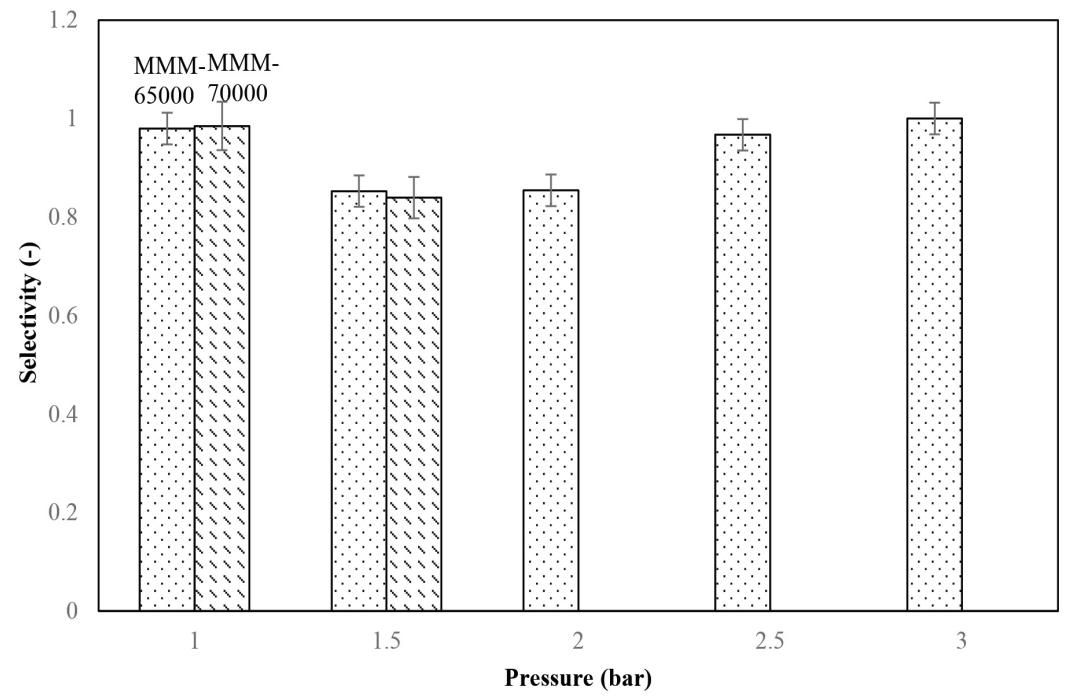

Figure 27: $\mathrm{CO}_{2} / \mathrm{N}_{2}$ selectivity of MMMs prepared with casting thickness of $250 \mu \mathrm{m}$ and MWCNT loading of $0.7 \mathrm{wt} \%$ with different $\mathrm{Mn}$ of 70000 and 65000. 


\section{CONCLUSION}

In this study, the optimum solvent evaporation time for the CAB membrane was $5 \mathrm{~min}$, while the optimum solvent exchange time was $30 \mathrm{~min}$ for both 2-isopropyl alcohol and n-hexane solvents (M7). As regards to $\mathrm{M} 7$, the $\mathrm{CO}_{2}$ permeance, $\mathrm{N}_{2}$ permeance, and selectivity obtained were $322.603 \pm 0.467 \mathrm{GPU}, 329.769 \pm$ $0.685 \mathrm{GPU}$, and $0.978 \pm 0.011 \mathrm{GPU}$, respectively. To further improve the CAB membrane performance towards the $\mathrm{CO}_{2} / \mathrm{N}_{2}$ gas separation, the functionalised MWCNTs were embedded into the CAB polymer structure in order to fabricate the MMM. Based on the results obtained, the MMM prepared with CAB polymer of molecular weight 65000 and MWCNTs loading of $0.1 \mathrm{wt} \%$ was proved to have high gas separation performances of $351.152 \pm 2.464 \mathrm{GPU}$ for $\mathrm{CO}_{2}$ permeance, and $2.935 \pm 0.062$ for $\mathrm{CO}_{2} / \mathrm{N}_{2}$ selectivity, respectively. This was as a result of the high acetyl content ( $28 \mathrm{wt} \%$ to $31 \mathrm{wt} \%$ ) of the $\mathrm{CAB}$ polymer.

\section{ACKNOWLEDGEMENTS}

The authors would like to extend our appreciation to the Ministry of Higher Education Malaysia (MOHE) for approving the Fundamental Research Grand Scheme (FRGS) (MOHE Ref No: FRGS/1/2015/TK02/CURTIN/03/01) and Cost Centre: 001048. We would also like to thank LRGS USM (Account No: 304/ PJKIMIA/6050296/U124) and Curtin Cost Centre: 001047.

\section{REFERENCES}

1. Global Carbon Budget. (2017). Highlights. Retrieved 19 November 2017 from http://www.globalcarbonproject.org/carbonbudget/17/highlights.htm.

2. Leung, D. Y. C., Giorgio, C. \& Mercedes, M-V. M. (2014). An overview of current status of carbon dioxide capture and storage technologies. J. Renew. Sustain. Energy, 39, 426-443, https://doi.org/10.1016/j.rser.2014.07.093.

3. Bhunia S. et al. (2017). Triazine containing N-rich microporous organic polymers for $\mathrm{CO}_{2}$ capture and unprecedented $\mathrm{CO}_{2} / \mathrm{N}_{2}$ selectivity. J. Solid State Chem., 247,113-119.

4. Favre, E. (2007). Carbon dioxide recovery from post-combustion processes: Can gas permeation membranes compete with absorption? J. Membr. Sci., 294, 50-59, https://doi.org/10.1016/j.memsci.2007.02.007.

5. Yong, W. F. et al. (2018). New polyethersulfone (PESU) hollow fiber membranes for $\mathrm{CO}_{2}$ capture. J. Membr. Sci., 552, 305-314.

6. Nath, K. (2017). Membrane separation processes. New Delhi: PHI Learning.

7. Ismail, A. F. et al. (2011). Gas separation performance of polyethersulfone/multiwalled carbon nanotubes mixed matrix membranes. Sep. Purif. Technol., 80(1), 20-31, https://doi.org/10.1007/s11814-014-0281-2. 
8. Minhas, B. S. (1992). Cellulose acetate butyrate gas separation membrane. New York: W. R. Grace \& Co.

9. Wang, Y., Lau, W. W. Y. \& Sourirajan, S. (2006). Effects of membrane-making conditions and shrinkage treatment on morphology and performance of cellulose acetate butyrate membranes. Sep. Sci. Technol., 29(13), 1689-1704, https://doi. org/10.1080/01496399408002165.

10. Jami'an, W. N. R. et al. (2016). Effect of evaporation time on cellulose acetate membrane for gas separation. IOP Conf. Earth Environ. Sci., https://doi. org/10.1088/1755-1315/36/1/012008.

11. Paulsen, F. G., Shojaie, S. S. \& Krantz, W. B. (1994). Effect of evaporation step on macrovoid formation in wet-cast polymeric membrane. J. Membr. Sci., 91(3), 265-282, https://doi.org/10.1016/0376-7388(94)80088-X.

12. Jawad, Z. A. et al. (2015). Influence of solvent exchange time on mixed matrix membrane separation performance for $\mathrm{CO}_{2} / \mathrm{N}_{2}$ and a kinetic sorption study. J. Membr. Sci., 476, 590-601, https://doi.org/10.1016/j.memsci.2014.11.008.

13. Lui, A. \& Talbot, F. D. F. (1988). Studies on the solvent exchange techique for making dry cellulose acetate membranes for the separation of gaseous mixtures. $J$. Appl. Polym. Sci., 36, 1809-1820.

14. Robeson, L. M., (2008). The upper bound revisited. J. Membr. Sci., 320(1-2), 390400, https://doi.org/10.1016/j.memsci.2008.04.030.

15. Kim, S., Pechar, T. W. \& Marand, E. (2005). Poly(imide siloxane) and carbon nanotube mixed matrix membranes for gas separation. Desalin., 192(1-3), 330339.

16. Rivas, B. L., Sanchez, J. \& Palencia, M. (2017). Nanostructured polymer membranes organic membranes and polymers for the removal of pollutants. In Visaka, P. M. \& Nazarenko, O. (Eds.). Nanostructured polymer membranes. Ottawa: Scrivener Publishing.

17. Feng, Y., Zhang, J.-M. \& Zhang, J. (2015). Gas separation properties of cellulose acetate butyrate/MWCNTs mixed matrix membranes. Acta Polym. Sin., 12, 13961401, https://doi.org/10.11777/j.issn1000-3304.2015.15095.

18. Ahmad, A. L. et al. (2014). A cellulose acetate/multi-walled carbon nanotube mixed matrix membrane for $\mathrm{CO}_{2} / \mathrm{N}_{2}$ separation. J. Membr. Sci., 451, 55-66, https:// doi.org/10.1016/j.memsci.2013.09.043.

19. Chen, J., Dyer, M. J. \& Yu, M-F. (2001). Cyclodextrin-mediated soft cutting of single-walled carbon nanotubes. J. ACS, 123(25), 6201-6202.

20. Jawad, Z. A. et al. (2017). Binding stability of $\beta-C D$ on MWCNTS: Role of washing cycle on the $\beta$-CD coating. J. Phys. Sci., 28(Supp. 1), 145-153, https:// doi.org/10.21315/jps2017.28.s1.9.

21. Kohl, A. \& Nielsen, R. (1997). Gas purification. Houston: Gulf Publishing Company.

22. NanoScience Instruments. (2017). Scanning electron microscopy. Retrieved 5 November 2017 from http://www.nanoscience.com/technology/sem-technology/.

23. Lee, R. J. et al. (2017). Improvement of $\mathrm{CO}_{2} / \mathrm{N}_{2}$ separation performance by polymer matrix cellulose acetate butyrate. IOP Conf. Ser. Mater. Sci., https://doi. org/10.1088/1757-899X/206/1/012072. 
24. Silverstein, R. M., Bassler, G. C. \& Morrill, T. C. (1981). Spectrometric identification of organic compounds. New York: John Wiley \& Sons.

25. Zhang, Q., Lei, L. \& Zhu, S. (2017). Gas-responsive polymers. ACS Macro Lett., 6, 515-522, https://doi.org/10.1021/acsmacrolett.7b00245.

26. Fang, Y. et al. (1994). Effect of surface-modifying macromolecules and solvent evaporation time on the performance of polyethersulfone membranes for the separation of chloroform/water mixtures by pervaporation. J. Appl. Polym. Sci., 54.

27. Abdullah, S. N. A., Lau, W. J. \& Ismail, A. F. (2015). Morphologies and separation characteristics of polyphenylsulfone-based solvent resistant nanofiltration membranes: Effect of polymer concentration in casting solution and membrane pretreatment condition. Kor. J. Chem. Eng., 32(4), 743-752, https://doi. org/10.1007/s11814-014-0281-2.

28. Goh, P. S. et al. (2011). Recent advances of inorganic fillers in mixed matrix membrane for gas separation. Sep. Purif. Technol., 81(3), 243-264, https://doi. org/10.1016/j.seppur.2011.07.042.

29. Khan, M. M. et al. (2012). Functionalized carbon nanotubes mixed matrix membranes of polymers of intrinsic microporosity for gas separation. Nanos. Res. Lett., 7(1), 504, https://doi.org/10.1186/1556-276X-7-504.

30. Mahajan, R., Koros, W. J. \& Thundyil, M. (1999). Mixed matrix membranes: Important and challenging. Membr. Technol., 1999(105), 6-8, https://doi. org/10.1016/S0958-2118(00)80157-3.

31. Ma, P. C., Kim, J.-K. \& Tang, B. Z. (2006). Functionalization of carbon nanotubes using a silane coupling agent. Carbon, 44, 3232-3238, https://doi.org/10.1016/j. carbon.2006.06.032.

32. Dotto, G. L. \& Paulo, S. (2017). Frontiers in biomaterials: Chitosan based materials and its applications - Application of chitosan membranes for permeation and pervaporation. Abu Dhabi: Bentham Science Publisher.

33. Silva, E. A. d. et al. (2017). Polydimethylsiloxane membranes containing multiwalled carbon nanotubes for gas separation. Mater. Res., 20(6), https://doi. org/10.1590/1980-5373-mr-2016-0825.

34. Fontananova, E. et al. (2015). From hydrophobic to hydrophilic polyvinylidenefluoride (PVDF) membranes by gaining new insight into material's properties. RSC Adv., 1-3, https://doi.org/10.1039/C5RA08388E.

35. Salajkova, M. et al. (2013). Tough nanopaper structures based on cellulose nanofibers and carbon nanotubes. Compos. Sci. Technol., 87, 103-110.

36. Puleo, A. C., Paul, D. R. \& Kelley, S. S. (1989). The effect of degree of acetylation on gas sorption and transport behavior in cellulose acetate. J. Membr. Sci., 47(3), 301-332.

37. Zaini, L. H. et al. (2015). Effect of kenaf cellulose whiskers on cellulose acetate butyrate nanocomposites properties nanocellulose polymer nanocomposites. In (Ed). Thakur, V. K. Nanocellulose polymer nanocomposites. London: Scrivener Publishing, 341-354.

38. Carreon, A. M. (2017). Membranes for gas separation. New York: World Scientific. 